\title{
过渡金属催化 $\mathrm{CO}_{2}$ 氢化反应研究进展
}

\author{
黄文斌邱丽琪任方煜何良年* \\ (南开大学化学学院 元素有机化学国家重点实验室 天津 300071)
}

\begin{abstract}
摘要 二氧化碳 $\left(\mathrm{CO}_{2}\right)$ 是主要的温室气体, 由于人类过度使用化石资源导致大气中 $\mathrm{CO}_{2}$ 浓度增加, 进而引发全球环境问 题. 另一方面, $\mathrm{CO}_{2}$ 是一种理想的 $\mathrm{C}_{1}$ 资源，具有安全、储量丰富和廉价易得等优点. 因此如何将 $\mathrm{CO}_{2}$ 应用于有机合成以 获得化工产品与燃料, 已成为当前研究热点. 其中, 过渡金属催化的 $\mathrm{CO}_{2}$ 氢化反应是 $\mathrm{CO}_{2}$ 资源化利用的重要途径, 反应 可以在温和条件下选择性地生成 $2 \mathrm{e} 、 4 \mathrm{e}$ 和 $6 \mathrm{e}$ 还原产物，如甲酸、甲酰胺、甲酸酯、甲醛、甲醇以及 $\mathrm{C}_{2}+$ 醇等产物，具 有广阔的应用前景, 因此引人注目. 系统总结了近来过渡金属配合物催化 $\mathrm{CO}_{2}$ 加氢反应的研究进展, 主要对催化剂的 种类和结构、活性及其产物选择性等进行总结, 并对近来所发展的与 $\mathrm{CCU}\left(\mathrm{CO}_{2}\right.$ capture and utilization)策略相关的 $\mathrm{CO}_{2}$ 原位催化氢化反应进行了分析与讨论. 此外, 对本领域中存在的挑战及展望进行了分析.
\end{abstract}

关键词 二氧化碳; 金属有机配合物; 均相催化; 氢化反应; 可持续化学

\section{Advances on Transition-Metal Catalyzed $\mathrm{CO}_{2}$ Hydrogenation}

\author{
Huang, Wenbin Qiu, Liqi Ren, Fangyu He, Liangnian* \\ (State Key Laboratory of Elemento-organic Chemistry, College of Chemistry, Nankai University, Tianjin 300071)
}

\begin{abstract}
Carbon dioxide $\left(\mathrm{CO}_{2}\right)$ is the main greenhouse gas, the excessive burning of fossil fuels leads to the increasing of $\mathrm{CO}_{2}$ concentration, resulting in global warming. On the other hand, $\mathrm{CO}_{2}$ is regarded as an ideal $\mathrm{C}_{1}$ source due to its nontoxicity, abundance and availability. Hence, the transformation of $\mathrm{CO}_{2}$ into fine chemicals and hydrocarbon fuels in organic synthesis is becoming one of hot research fields. Among them, the transition-metal catalyzed $\mathrm{CO}_{2}$ hydrogenation is an appealing and promising approach for $\mathrm{CO}_{2}$ utilization with wide potential applications, thus leading to selective fromation of $2 \mathbf{e}$, $4 \mathbf{e}$, and $6 \mathrm{e}$ reductive products including formic acid, formamide, formate, formaldehyde, methanol and $\mathrm{C}_{2+}$ alcohols under mild reaction conditions. In this review, the recent advances on transition metal complexe-catalyzed $\mathrm{CO}_{2}$ hydrogenation are in detail summarized on the basis of the molecular structures, activities of the homogeneous catalysts, and product selectivity controlling. This review also gives an overview on the in situ catalytic hydrogenation corresponding to the recently developed CCU $\left(\mathrm{CO}_{2}\right.$ capture and utilization) strategy. Furthermore, the challenges and perspectives in homogeneous catalytic hydrogenation field are also given in this article.
\end{abstract}

Keywords carbon dioxide; organometallic complexes; homogeneous catalysis; hydrogenation; sustainable chemistry

随着社会经济的快速发展, 过度使用化石资源导致 严重的环境问题, 其中温室效应的加剧影响到人类的生 活. 化石燃料(煤、石油、天然气等)的燃烧成为了 $\mathrm{CO}_{2}$ 排放的主要来源, 目前每年大约有 300 亿吨的 $\mathrm{CO}_{2}$ 是通 过燃烧化石燃料释放到大气中[1]. 大气中 $\mathrm{CO}_{2}$ 的含量如 果以当前的速度增加, 那么全球气温在 21 世纪末将升 高 $6{ }^{\circ} \mathrm{C}$, 伴随的后果是全球冰川融化, 海平面上升, 土 地沙漠化加剧等. 我国提出将力争 $\mathrm{CO}_{2}$ 排放在 2030 年 前达到峰值, 2060 年前实现碳中和 ${ }^{[2]}$. 因此, $\mathrm{CO}_{2}$ 资源化
利用对于减少化石资源的依赖以及减缓温室效应具有 重要意义.

利用可再生的清洁能源替代化石燃料, 在一定程度 上可以实现节能减排, 减缓温室效应. 另一方面, 可以 将 $\mathrm{CO}_{2}$ 作为 $\mathrm{C}_{1}$ 合成子实现高附加值化学品的合成 ${ }^{[3]}$, 对 于可持续发展具有重要意义. $\mathrm{CO}_{2}$ 的化学转化类型可以 分为如下几种: (1)偶联反应, 例如羧化、羧化环化等, 相 应产物为羒酸及其衍生物、环状碳酸酯、噁唑啉酮及氨 基甲酸酯等; (2)光电还原反应, 主要产物为甲酸、甲醛、

\footnotetext{
* Corresponding author. E-mail: heln@nankai.edu.cn

Received May 31, 2021; revised June 19, 2021; published online July 5, 2021.

Dedicated to the 100th anniversary of Chemistry at Nankai University.

Project supported by the National Natural Science Foundation of China (No. 21975135).

国家自然科学基金(No. 21975135)资助项目.
} 
甲醇、甲烷以及 $\mathrm{CO}$ 等; (3)催化氢化反应，产物为甲酸、 甲酰胺、甲酸酯、甲醛、甲醇以及短链烷烃等; (4)生物 固定, 产物为糖类、乙酸和乙醇等; (5)甲烷重整, 主要得 到合成气( $\mathrm{CO}$ 和 $\left.\mathrm{H}_{2}\right)$; (6)工业合成碳酸盐, 如碳酸钠、碳 酸氢钠等. 在众多 $\mathrm{CO}_{2}$ 资源化利用的方法中, 其中 $\mathrm{CO}_{2}$ 的催化氢化是最具吸引力和符合 “绿色化学” 理念, 并 具有工业化应用前景. $\mathrm{CO}_{2}$ 的催化氢化反应是指在催化 剂作用下, 使用 $\mathrm{H}_{2}$ (或其他氢源) 对 $\mathrm{CO}_{2}$ 进行加氢还原生 成甲酸、甲酰胺、甲酸酯、甲醛、甲醇以及短链烷烃等 高能有机小分子的过程. 本综述从 $\mathrm{CO}_{2}$ 的氢化产物类型 包括 $2 \mathrm{e}$ (甲酸, 甲酰胺和甲酸酯等), $4 \mathrm{e}$ (甲醛)和 $6 \mathrm{e}$ (甲醇) 还原产物, 以及催化剂的种类和结构进行分类总结, 旨 在探究不同催化体系的反应机理, 归纳总结配体(单膦、 双膦、Pincer 和 Triphos 配体等)对催化活性及产物选择 性的影响规律, 希望为认识 $\mathrm{CO}_{2}$ 的均相催化氢化机制, 进而为催化剂的理性设计提供借鉴.

\section{1 两电子氢化产物}

将 $\mathrm{CO}_{2}$ 进行氢化还原至甲酸、甲酰胺以及甲酸酯等 产物, 是 $2 \mathrm{e}$ 还原过程. 甲酸在工业上被广泛用于皮革、 纺织品和乳胶的生产 ${ }^{[4]}$. 引人注目的是, Williams 等提 出利用 $\mathrm{CO}_{2}$ 氢化为甲酸进行储氢, 同时将能量储存起 来, 因此甲酸可以作为一种重要的液态储氢材料. 在这 个过程中, 甲酸常被作为一种 $\mathrm{H}_{2}$ 以及能量的载体 ${ }^{[5]}$. 甲 酸的衍生物甲酰胺在工业上被广泛用作溶剂和原材料, 例如, $N, N$-二甲基甲酰胺(DMF) 具有很大的全球市场年 交易量, 超过了 60 万吨/年. 同时, DMF 还可以作为有 机合成子, 可以发生腈基化、胺甲酰化、胺化以及环加 成等反应 ${ }^{[6]}$. 尽管非均相催化体系可以实现 $\mathrm{CO}_{2}$ 的氢化 合成甲酸及其衍生物, 具有操作连续化, 催化及易分离 与循环使用, 便于工业放大等优点, 但在非均相条件下, 相对于均相催化, 活性减低低, 大部分非均相分子催化 剂的 $\mathrm{TON}<10000, \mathrm{TOF}<3000 \mathrm{~h}^{-1}\left[{ }^{[7]}\right.$. 相对而言, 均相 催化具有反应速率快, 产物选择性高、便于均相反应机 理研究等优点, 因此受到广泛关注. 现有的甲酸合成工 艺是利用 $\mathrm{CO}$ 对甲醇进行羰基化再水解的过程, 与此相 比, $\mathrm{CO}_{2}$ 氢化合成甲酸反应步骤简洁，原子经济性 $100 \%$, 具有发展前景. 但是反应的吉布斯自由能 $(\Delta G)$ 为正值
(表 1, Eq. 1), 热力学不利; 因此, 加入碱促进反应的进 行(表 1 , Eqs. 2, 3) ${ }^{[8]}$. 以下将从催化剂的类型进行分类介 绍 $2 \mathrm{e}$ 氢化还原 $\mathrm{CO}_{2}$ 的催化体系(表 2), 产物主要有甲 酸、甲酰胺和甲酸酯.

\section{1 贵金属催化体系}

\subsection{1 $\mathrm{Ru}$ 催化体系}

$\mathrm{CO}_{2}$ 氢化为甲酸的反应已经研究了近 90 年, 催化剂 的开发从未间断. 早在 1935 年 Farlow 和 Adkins 等 ${ }^{[9]}$ 报 道了非均相雷尼镍催化 $\mathrm{CO}_{2}$ 氢化合成甲酸. 我们将重点 介绍均相催化 $\mathrm{CO}_{2}$ 氢化制备甲酸及其衍生物的发展过 程. 直到 1976 年, Inoue 等 ${ }^{[10]}$ 报道了首例均相催化 $\mathrm{CO}_{2}$ 氢化为甲酸的例子. 对 $\mathrm{Ru} 、 \mathrm{Rh} 、 \mathrm{Ir} 、 \mathrm{Pd}$ 和 $\mathrm{Ni}$ 的金属配 合物以及单膦、双膦配体进行篎选, 结果表明 $\left[\mathrm{Ru}(\mathrm{H})_{2}\right.$ $\left(\mathrm{PPh}_{3}\right)_{4}$ ] 催化活性最好, 在温和条件下 $\left(P_{\mathrm{CO}_{2}}=2.5 \mathrm{MPa}\right.$, $\left.P_{\mathrm{H}_{2}}=2.5 \mathrm{MPa}, 25{ }^{\circ} \mathrm{C}\right)$, 最高 TON 达 87. 1994 年, Jessop 与 Noyori 等 ${ }^{[12}$ 使用 $\mathrm{RuCl}_{2}\left[\mathrm{PMe}_{3}\right]_{4}$ 作催化剂, 超临界 $\mathrm{CO}_{2}$ 作为反应溶剂, 在较为温和的反应条件下 $\left(P_{\mathrm{CO}_{2}}=1.3\right.$ $\left.\mathrm{MPa}, P_{\mathrm{H}_{2}}=8.0 \mathrm{MPa}, 100{ }^{\circ} \mathrm{C}\right)$, 高效地实现了 $\mathrm{CO}_{2}$ 的氢化 (图 1), TON 高达 370000 . 其中, 二甲胺、甲酸和 DMF 的动态研究表明, 反应分两步进行: (1)甲酸的生成, (2) 甲酸与胺的缩合.

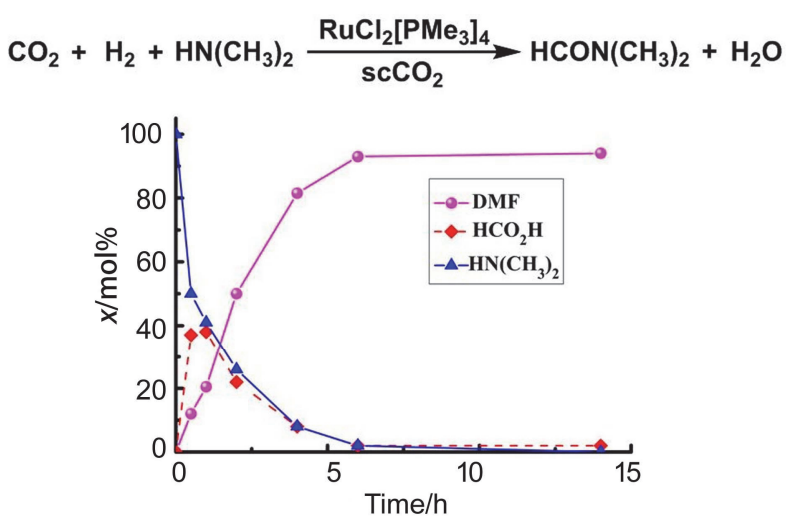

图 1 二甲胺、甲酸、DMF 含量与时间的函数 Figure 1 Composition of dimethylamine, formic acid and DMF as a function of reaction time

随后, Baiker 课题组 ${ }^{[13]}$ 使用 $\left[\mathrm{RuCl}_{2}(\mathrm{dppe})_{2}\right]$ 催化剂能 在温和条件下 $\left(P_{\mathrm{CO}_{2}}=13 \mathrm{MPa}, P_{\mathrm{H}_{2}}=8.5 \mathrm{MPa}, 100{ }^{\circ} \mathrm{C}\right)$, 以 $\mathrm{TON}=740000, \mathrm{TOF}=360000 / \mathrm{h}^{-1}$ 实现 $\mathrm{CO}_{2}$ 氢化生成

表 1 二氧化碳及碳酸氢盐的氢化反应热力学数据 ${ }^{[8]}$

Table 1 Thermodynamic data for hydrogenation of $\mathrm{CO}_{2}$ and bicarbonate

\begin{tabular}{|c|c|c|c|}
\hline Reaction equation & $\Delta G^{\mathrm{o}} /\left(\mathrm{kJ} \cdot \mathrm{mol}^{-1}\right)$ & $\Delta H^{\mathrm{o}} /\left(\mathrm{kJ} \cdot \mathrm{mol}^{-1}\right)$ & Eq. \\
\hline $\mathrm{CO}_{2}(\mathrm{~g})+\mathrm{H}_{2}(\mathrm{~g}) \rightarrow \mathrm{HCOOH}(\mathrm{l})$ & +32.9 & -31.2 & (1) \\
\hline $\mathrm{CO}_{2}(\mathrm{~g})+\mathrm{H}_{2}(\mathrm{~g})+\mathrm{NH}_{3}(\mathrm{aq}) \rightarrow \mathrm{HCO}_{2}^{-}(\mathrm{aq})+\mathrm{NH}_{4}^{+}(\mathrm{aq})$ & -9.5 & -84.3 & (2) \\
\hline $\mathrm{CO}_{2}(\mathrm{aq})+\mathrm{H}_{2}(\mathrm{aq})+\mathrm{NH}_{3}(\mathrm{aq}) \rightarrow \mathrm{HCO}_{2}^{-}(\mathrm{aq})+\mathrm{NH}_{4}{ }^{+}(\mathrm{aq})$ & -35.4 & -59.8 & (3) \\
\hline $\mathrm{MHCO}_{3}(\mathrm{aq})+\mathrm{H}_{2}(\mathrm{aq}) \rightarrow \mathrm{HCO}_{2} \mathrm{M}(\mathrm{aq})+\mathrm{H}_{2} \mathrm{O}(\mathrm{l})$ & -0.7 & -20.5 & (4) \\
\hline
\end{tabular}


表 $2 \mathrm{CO}_{2} /$ 碳酸氢盐氢化的典型体系

Table 2 Selected catalytic systems for the hydrogenation of $\mathrm{CO}_{2} /$ bicarbonate

\begin{tabular}{|c|c|c|c|c|c|c|c|c|}
\hline Catalyst precursor & Solvent & Additive & $P\left(\mathrm{CO}_{2} / \mathrm{H}_{2}\right) / \mathrm{MPa}$ & $T /{ }^{\circ} \mathrm{C}$ & Time/h & TON & $\mathrm{TOF} / \mathrm{h}^{-1}$ & Ref. \\
\hline$\left[\mathrm{RuH}_{2}\left(\mathrm{PPh}_{3}\right)_{4}\right]$ & $\mathrm{C}_{6} \mathrm{H}_{6} / \mathrm{H}_{2} \mathrm{O}$ & $\mathrm{NEt}_{3}$ & $2.5 / 2.5$ & r.t. & 20 & 87 & 4 & [10] \\
\hline$\left[\mathrm{RuH}_{2}\left(\mathrm{PMe}_{3}\right)_{4}\right]$ & $\mathrm{scCO}_{2}$ & $\mathrm{NEt}_{3} / \mathrm{H}_{2} \mathrm{O}$ & $12 / 8.5$ & 50 & 1 & 3700 & 1400 (initial) & [11] \\
\hline$\left[\mathrm{RuH}_{2}\left(\mathrm{PMe}_{3}\right)_{4}\right]$ & $\mathrm{scCO}_{2}$ & $\mathrm{NHMe}_{2}$ & $13 / 8$ & 100 & 14 & 370000 & 26428 & [12] \\
\hline$\left[\mathrm{RuCl}_{2}(\mathrm{dppe})_{2}\right]$ & $\mathrm{scCO}_{2}$ & $\mathrm{NHMe}_{2}$ & $13 / 8.5$ & 100 & 2.05 & 740000 & 360000 & [13] \\
\hline$\left[\mathrm{RuCl}(\mathrm{OAc})\left(\mathrm{PMe}_{3}\right)_{4}\right]$ & $\mathrm{scCO}_{2}$ & $\mathrm{NEt}_{3} / \mathrm{C}_{6} \mathrm{~F}_{5} \mathrm{OH}$ & $12 / 7$ & 50 & 0.3 & 31200 & 95000 & [14] \\
\hline$\left[\left(\mathrm{C}_{6} \mathrm{Me}_{6}\right) \mathrm{Ru}(\mathrm{DHPHEN}) \mathrm{Cl}\right] \mathrm{Cl}$ & $\mathrm{H}_{2} \mathrm{O}$ & $\mathrm{KOH}$ & $3 / 3$ & 120 & 24 & 15400 & 640 & [15] \\
\hline$\left[\mathrm{RuCl}_{2}\left(\mathrm{C}_{6} \mathrm{H}_{6}\right)\right]_{2} / \mathrm{DPPM}$ & $\mathrm{H}_{2} \mathrm{O} / \mathrm{THF}$ & $\mathrm{NaHCO}_{3}$ & $0 / 5$ & 70 & 2 & 1400 & 690 & [16] \\
\hline$\left[\left(\eta^{6}-p\right.\right.$-Cymene $\left.) \mathrm{Ru}(\mathrm{bis}-\mathrm{NHC}) \mathrm{Cl}\right] \mathrm{PF}_{6}$ & $\mathrm{H}_{2} \mathrm{O}$ & $\mathrm{KOH}$ & $2 / 2$ & 200 & 75 & 23000 & 300 & {$[17]$} \\
\hline$[(\mathrm{PNP}) \mathrm{RuH}(\mathrm{Cl})(\mathrm{CO})]$ & $\mathrm{MeOH} / \mathrm{H}_{2} \mathrm{O}$ & $\mathrm{KOH} / \mathrm{KHCO}_{3}$ & - & 150 & 36 & 18420 & 510 & [18] \\
\hline$\left[(\mathrm{PNP}) \mathrm{RuH}\left(\mathrm{H}-\mathrm{BH}_{3}\right)(\mathrm{CO})\right]$ & $\mathrm{H}_{2} \mathrm{O} / \mathrm{THF}$ & $\mathrm{Na}_{2} \mathrm{CO}_{3}$ & $1.2 / 3.8$ & 79 & 1 & 2200 & 2100 & [19] \\
\hline$[(\mathrm{PNN}) \mathrm{RuH}(\mathrm{CO})$ & Diglyme & $\mathrm{K}_{2} \mathrm{CO}_{3}$ & $1.0 / 3.0$ & 200 & 48 & 23000 & 480 & [20] \\
\hline$[\mathrm{RuCl}(\mathrm{H}) \mathrm{CO}(\mathrm{PNP})]$ & THF & Morpholine & $3.5 / 3.5$ & 120 & 96 & 1940000 & 20208 & [21] \\
\hline$\left[\mathrm{Ru}(\right.$ Acriphos $\left.)\left(\mathrm{PPh}_{3}\right)(\mathrm{Cl})\left(\mathrm{PhCO}_{2}\right)\right]$ & $\mathrm{DMSO} / \mathrm{H}_{2} \mathrm{O}$ & Acetate buffer & $4 / 8$ & 60 & 16 & 16310 & 1019 & [22] \\
\hline $\mathrm{Ru} / \mathrm{PNNN}$ & ${ }^{i} \mathrm{PrOH}$ & ${ }^{t} \mathrm{BuOK}$ & $4 / 4$ & 90 & 30 & 300000 & 10000 & [24] \\
\hline$\left[\mathrm{RhCl}(\mathrm{TPPTS})_{3}\right]$ & $\mathrm{H}_{2} \mathrm{O}$ & $\mathrm{NHMe}_{2}$ & $2 / 2$ & r.t. & 12 & 3400 & 280 & {$[31]$} \\
\hline$\left[\mathrm{RhCl}\left(\mathrm{PPh}_{3}\right)_{3}\right] / \mathrm{PPh}_{3}$ & $\mathrm{MeOH} / \mathrm{DMSO}$ & $\mathrm{NEt}_{3}$ & $4 / 2$ & r.t. & 20 & 2500 & 125 & [32] \\
\hline $\mathrm{RhCl}_{3} \cdot 3 \mathrm{H}_{2} \mathrm{O} / \mathrm{CyPPh}_{2}$ & $\mathrm{MeOH}$ & $\mathrm{PEI}_{600}$ & $4 / 4$ & 60 & 32 & 852 & 27 & [33] \\
\hline$[\mathrm{Cp} * \operatorname{Ir}(\mathrm{DHPHEN}) \mathrm{Cl}] \mathrm{Cl}$ & $\mathrm{H}_{2} \mathrm{O}$ & $\mathrm{KOH}$ & $3 / 3$ & 120 & 1 & 21000 & 23000 & [15] \\
\hline$\left[(\mathrm{Cp} * \mathrm{Ir})_{2}(\mathrm{THBPM})\left(\mathrm{H}_{2} \mathrm{O}\right)_{2}\right]\left(\mathrm{SO}_{4}\right)_{2}$ & $\mathrm{H}_{2} \mathrm{O}$ & $\mathrm{KHCO}_{3}$ & $2.5 / 2.5$ & 80 & 1 & 79000 & 53800 & [43] \\
\hline$\left[(\mathrm{PNP}) \mathrm{IrH}_{3}\right]$ & $\mathrm{H}_{2} \mathrm{O} / \mathrm{THF}$ & $\mathrm{KOH}$ & $3 / 3$ & 120 & 48 & 3500000 & 73000 & [37] \\
\hline$\left[(\mathrm{PNP}) \mathrm{IrH}_{2}(\mathrm{OOCH})\right]$ & $\mathrm{H}_{2} \mathrm{O}$ & $\mathrm{KOH}$ & $2.8 / 2.8$ & 185 & 2 & 37300 & 18600 & [38] \\
\hline$\left[\mathrm{Cp}^{*} \operatorname{Ir}\left(N, N^{\prime}\right) \mathrm{Cl}\right] \mathrm{Cl}$ & $\mathrm{H}_{2} \mathrm{O}$ & - & $2.5 / 2.5$ & 80 & 0.08 & 1100 & 13000 & [44] \\
\hline
\end{tabular}

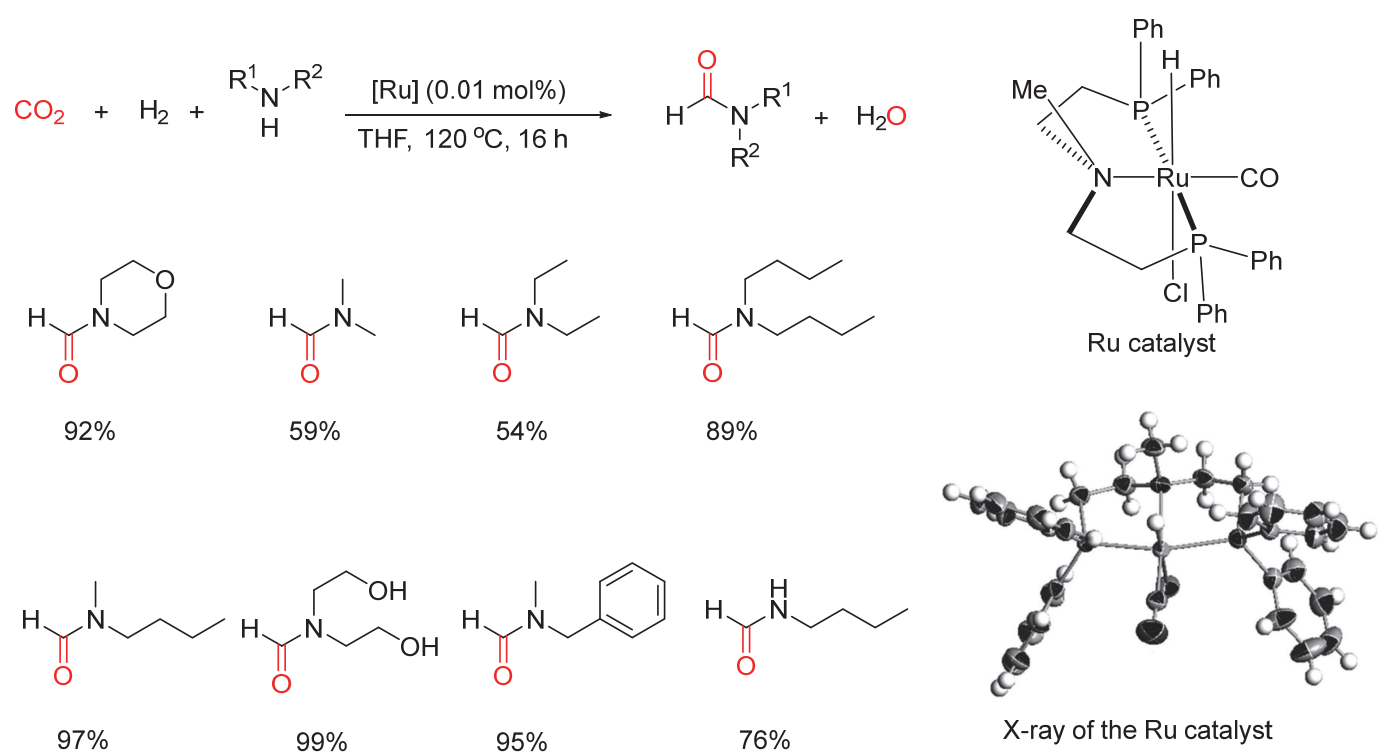

图式 $1 \mathrm{Ru} / \mathrm{PNP}$ 配合物催化 $\mathrm{CO}_{2}$ 氢化为甲酰胺

Scheme $1 \mathrm{Ru} / \mathrm{PNP}$ complex employed in the hydrogenation of $\mathrm{CO}_{2}$ to formamide

DMF. 由此可见, 配体的选择对于催化活性起着决定性 作用, 最突出的代表是, 2015 年丁奎岭等 ${ }^{[21]}$ 使用 $\mathrm{Ru} /$

Pincer 催化剂实现甲酰胺的合成(Scheme 1). 该催化剂
可以在温和条件下 $\left(P_{\mathrm{CO}_{2}}=P_{\mathrm{H}_{2}}=3.5 \mathrm{MPa}, 120{ }^{\circ} \mathrm{C}\right)$ 将 $\mathrm{CO}_{2}$ 氢化为甲酰胺，最高 TON 高达 1940000 ; 且可多次循环 使用，目前已完成了中试放大，有望实现大规模生产. 
上述的体系中, 需要胺类化合物作为碱促进氢化反 应的进行. 然而对于无碱条件下生成甲酸的例子则少有 报道. 2016 年, Leitner 课题组 ${ }^{[22]}$ 发展了新型的 [Ru$($ Acriphos $\left.)\left(\mathrm{PPh}_{3}\right)(\mathrm{Cl})\left(\mathrm{PhCO}_{2}\right)\right]$ [Acriphos $=4,5$-bis(diphenylphosphino) acridine]催化剂(Scheme 2), 可在二甲基亚 砜(DMSO)或 $\mathrm{DMSO} / \mathrm{H}_{2} \mathrm{O}$ 体系中在无碱存在下将 $\mathrm{CO}_{2}$ 氢化还原为甲酸. 该体系最高 TON 可达 4200 , TOF 为 $260 \mathrm{~h}^{-1}$. 不过, 所生成的甲酸浓度相对较低, 仅为 0.33 $\mathrm{mol} \cdot \mathrm{L}^{-1}$. 可能是由于生成的甲酸抑制了 $\mathrm{Ru}$ 催化剂的活 性, 因此向反应体系中加入少量的乙酸缓冲溶液, 可以 大幅度地提高甲酸的浓度, 最高达到 $1.27 \mathrm{~mol} \cdot \mathrm{L}^{-1}$, 此 时对应的 TON 为 16310 , TOF 为 $1019 \mathrm{~h}^{-1}$.

随后, Dupont 课题组 ${ }^{[23]}$ 报道了离子液体 1,2-二甲基3 -丁基咪唑・醋酸盐 $(\mathrm{BMMI} \cdot \mathrm{OAc})$ 与 $\left[\mathrm{Ru}_{3}(\mathrm{CO})_{12}\right]$ 形成的协 同催化体系(Scheme 3), 实现 $\mathrm{CO}_{2}$ 氢化还原为 $1.2 \mathrm{~mol} / \mathrm{L}$ 的甲酸溶液, 其催化效率较高 $\left(\mathrm{TOF}=102.4 \mathrm{~h}^{-1}, \mathrm{TON}=\right.$ 17000). 醋酸咪唑离子液体被视为催化剂的前驱体, 同 时起到了稳定活性中间体; 离子液体还可作为酸缓冲 液, 调节游离甲酸的平衡等作用.

为了探索配体的差异性对氢化活性的影响, 在 $\mathrm{Ru} /$ PNP 配合物的基础上, 周其林课题组 ${ }^{[24]}$ 发展了一种新型 的四齿联吡啶 $\mathrm{Ru}$ 配合物, 可高效催化 $\mathrm{CO}_{2}$ 的氢化生成 甲酰胺. 将催化剂和叔丁醇钾的用量增加十倍, 甲酰胺 被进一步反应形成甲醇和胺, 此外, 在二甲胺存在下直 接将 $\mathrm{CO}_{2}$ 氢化生成甲醇, TON 分别达到 300000,9800 , 2100 (Scheme 4). 结果表明, 四齿联吡啶配体可以提高 $\mathrm{Ru}$ 催化剂的稳定性, 对于提高氢化反应的效率起到了 决定性的作用.
甲酸酯同样是 $\mathrm{CO}_{2}$ 的 $\mathbf{2 e}$ 还原产物之一. Klanker-

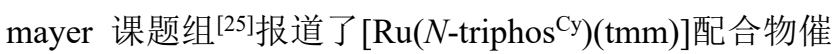
化 $\mathrm{CO}_{2}$ 氢化为甲酸酯的例子 (Scheme 5). 该催化剂能与 路易斯酸 $\mathrm{Al}(\mathrm{OTf})_{3}$ 协同作用, 促进 $\mathrm{CO}_{2}$ 选择性氢化还原 为甲酸酯类产物. 机理研究表明, 首先是 $\mathrm{CO}_{2}$ 被氢化还 原为甲酸, 随后在 $\mathrm{Al}(\mathrm{OTf})_{3}$ 的作用下与甲醇发生酯化反 应生成甲酸酯类产物.

在上述的诸多报道中, 大多数反应倾向于使用膦配 体, 然而对于氮氧配体的研究却很少. 2020 年, Makhubela 课题组 ${ }^{[26]}$ 报道了 $\mathrm{Ru}(\mathrm{II}) 、 \mathrm{Rh}(\mathrm{III}) 、 \mathrm{Ir}(\mathrm{II})$ 和 $\mathrm{Os}(\mathrm{II})$ 的半 三明治结构的配合物用于 $\mathrm{CO}_{2}$ 氢化还原为甲酸盐, 展现 出了较好的催化活性. 催化剂结构中, 配体的氮和氧原 子与中心金属进行配位, $R h(I I I)$ 和 $\operatorname{Ir}(\mathrm{III})$ 配合物的稳定性 高于 $\mathrm{Ru}(\mathrm{II})$ 和 Os(II) 催化剂(Scheme 6). 此外, 以 $\mathrm{DBU}$ 作 为碱, $\mathrm{Ru}(\mathrm{II})$ 配合物可在相对温和的反应条件下 $P\left(\mathrm{CO}_{2} /\right.$ $\left.\mathrm{H}_{2}, V: V=1: 2\right)=6 \mathrm{MPa}, 120{ }^{\circ} \mathrm{C}$ 反应 $24 \mathrm{~h}, \mathrm{TON}=585$, $\mathrm{TOF}=30 \mathrm{~h}^{-1}$ )高效地催化 $\mathrm{CO}_{2}$ 氢化生成甲酸盐.

\subsubsection{Rh 催化体系}

除了 $\mathrm{Ru}$ 催化 $\mathrm{CO}_{2}$ 氢化反应外, $\mathrm{Rh}$ 催化也可以实现 这一转化. 1992 年, Nicholas 课题组 ${ }^{[27]}$ 报道了 $[\mathrm{Rh}(\mathrm{NBD})$ $\left.\left(\mathrm{PMe}_{2} \mathrm{Ph}\right)_{3}\right] \mathrm{BF}_{4}\left(\mathrm{NBD}=\right.$ norbornadiene)催化 $\mathrm{CO}_{2}$ 氢化还 原为甲酸的体系(Scheme 7), 反应可在温和的条件下进 行, $\mathrm{TOF}=10 \sim 60 / \mathrm{d}$. 少量水可促进反应的进行, 外加膦 配体 $\mathrm{PMe}_{2} \mathrm{Ph}$ 会抑制该反应, 可能是因为过多的膦配体 会包裹金属活性中心，从而阻碍了 $\mathrm{CO}_{2}$ 与 $\mathrm{Rh}$ 中心配位. 通过机理实验证明，中间体 7 中甲酸产物的还原消除过 程是整个反应的决速步.

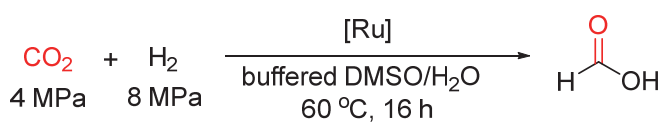

\begin{tabular}{|c|c|c|c|c|c|}
\hline Entry & Solvent & Additive $/\left(\mathrm{mol} \cdot \mathrm{L}^{-1}\right)$ & $c(\mathrm{HCOOH}) /\left(\mathrm{mol} \cdot \mathrm{L}^{-1}\right)$ & TON & $\mathrm{TOF} / \mathrm{h}^{-1}$ \\
\hline 1 & $95 \%$ DMSO 5\% Water & - & 0.33 & 4200 & 260 \\
\hline 2 & $95 \%$ DMSO 5\% Water & Acetate buffer $(0.4)$ & 1.27 & 16310 & 1019 \\
\hline
\end{tabular}

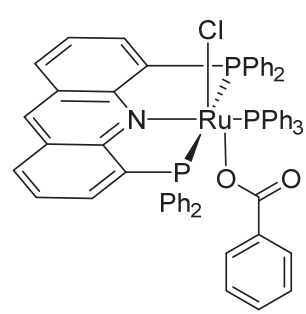

Ru catalyst

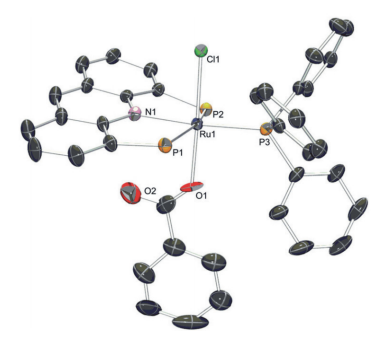

X-ray of the Ru catalyst

图式 $2 \mathrm{DMSO} / \mathrm{H}_{2} \mathrm{O}$ 体系中 $\mathrm{CO}_{2}$ 氢化为甲酸

Scheme 2 Hydrogenation of $\mathrm{CO}_{2}$ to formic acid in $\mathrm{DMSO} / \mathrm{H}_{2} \mathrm{O}$ 


$$
\mathrm{CO}_{2}+\mathrm{H}_{2} \frac{\mathrm{BMMl} \cdot \mathrm{OAc} /\left[\mathrm{Ru}_{3}(\mathrm{CO})_{12}\right]}{\begin{array}{c}
\left(3 \mathrm{MPaCO} \mathrm{CO}_{2} / 4 \mathrm{MPa} \mathrm{H}\right. \\
\mathrm{T}=70^{\circ} \mathrm{C}, 168 \mathrm{~h}
\end{array}} \mathrm{HCOOH}\left[\begin{array}{l}
\mathrm{TON}=17000 \\
\mathrm{TOF}=102.4 \mathrm{~h}^{-1}
\end{array}\right.
$$

图式 $3 \mathrm{Ru}$ /离子液体协同催化 $\mathrm{CO}_{2}$ 氢化还原为甲酸

Scheme $3 \mathrm{Ru}$ /ionic liquids cooperative catalysis for the hydrogenation of $\mathrm{CO}_{2}$ to formic acid

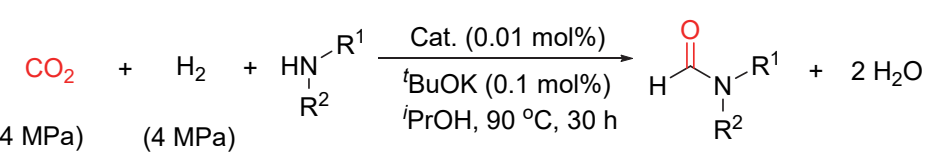

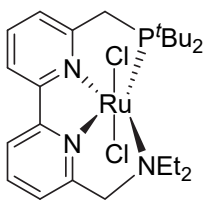

Ru catalyst<smiles>O=CNCc1ccccc1</smiles>

$72 \%$<smiles>CN(C)C=O</smiles>

$68 \%$<smiles>CC(NC=O)c1ccccc1</smiles>

$78 \%$<smiles>O=CN1CCCC1</smiles>

$70 \%$<smiles>CCCCNC=O</smiles>

$72 \%$<smiles>O=CN1CCCCC1</smiles>

$80 \%$<smiles>O=CNCCO</smiles>

$85 \%$

图式 $4 \mathrm{Ru}$ 催化 $\mathrm{CO}_{2}$ 氢化合成甲酰胺

Scheme 4 Ru-catalyzed hydrogenation of $\mathrm{CO}_{2}$ to formamides

$$
\begin{aligned}
& \underset{3 \mathrm{MPa}}{\mathrm{CO}_{2}}+\underset{9 \mathrm{MPa}}{\mathrm{H}_{2}}+\mathrm{MeOH} \frac{\left[\mathrm { Ru } \left(\mathrm{N} \text {-triphosCy)(tmm)], } \mathrm{Al}(\mathrm{OTf})_{3}\right.\right.}{\mathrm{MeOH} / 1,4-\text { dioxane, } 60^{\circ} \mathrm{C}, 64 \mathrm{~h}}+\mathrm{H}_{\mathrm{O}} \mathrm{CH}_{3}+\mathrm{H}_{2} \mathrm{O} \\
& \text { CON =9542 }
\end{aligned}
$$

图式 $5 \mathrm{Ru}$ 催化 $\mathrm{CO}_{2}$ 氢化合成甲酸酯

Scheme 5 Catalytic synthesis of methyl formate from $\mathrm{CO}_{2}$ and molecular hydrogen

Cat. $(0.009 \mathrm{mmol})$

$\mathrm{CO}_{2}+\mathrm{H}_{2}+\mathrm{DBU} \frac{\mathrm{THF} / \mathrm{H}_{2} \mathrm{O}(\mathrm{V}: \mathrm{V}=5: 1,6 \mathrm{~mL})}{120^{\circ} \mathrm{C}, 24 \mathrm{~h}}\left[\mathrm{HCO}_{2}\right]^{-}[\mathrm{DBU}-\mathrm{H}]^{+}$

$2 \mathrm{MPa} 4 \mathrm{MPa} 4 \mathrm{mmol}$

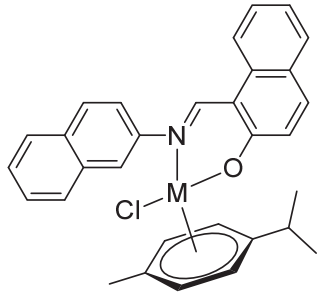

$M=\operatorname{Ru}(I I)$

$\mathrm{M}=\mathrm{Os}(\mathrm{II})$

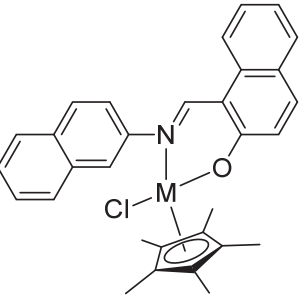

$M=\operatorname{Rh}(I I I)$

$M=\operatorname{lr}(\mathrm{III})$
图式 $6 \mathrm{Ru}$ 催化 $\mathrm{CO}_{2}$ 氢化合成甲酸盐

Scheme 6 Hydrogenation of $\mathrm{CO}_{2}$ to formate catalyzed by $\mathrm{Ru}$ complex

为了更好研究 $\mathrm{Rh}$ 催化 $\mathrm{CO}_{2}$ 氢化反应机理, 早在 1997 年, Leitner 课题组 ${ }^{[28]}$ 使用 $[(\mathrm{dppp}) \mathrm{Rh}$ (hfacac)]

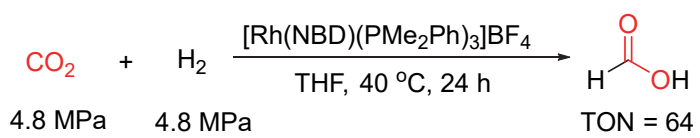

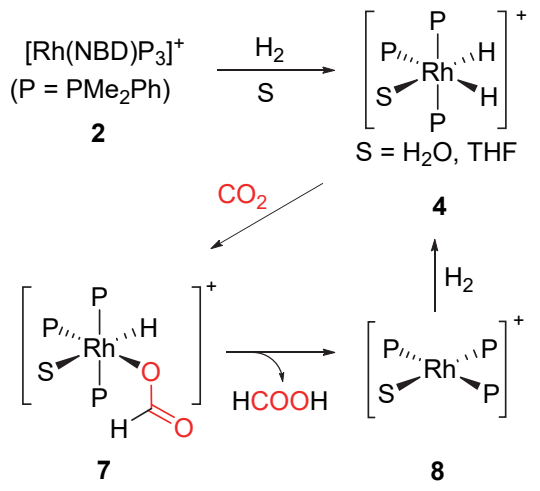

图式 $7 \mathrm{Rh}$ 催化 $\mathrm{CO}_{2}$ 氢化还原为甲酸

Scheme 7 Hydrogenation of $\mathrm{CO}_{2}$ to formic acid catalyzed by Rh complex 
$\left(\mathrm{dppp}=\mathrm{Ph}_{2} \mathrm{P}\left(\mathrm{CH}_{2}\right)_{3} \mathrm{PPh}_{2}\right.$, hfacac $=$ hexafluoroacetyl acetonate)作为催化剂模型进行 $\mathrm{CO}_{2}$ 氢化机理计算(图 2). 结 果表明, 在甲酸中间体形成以后, $\mathrm{H}_{2}$ 与之发生 $\sigma$ 键复分 解反应的途径相对于氧化加成一还原消除机制具有更低 的反应能垒, 更有利于氢化反应的进行, 这也是第一例 完整提出 $\mathrm{CO}_{2}$ 氢化历程的理论计算研究.

2019 年, 韩布兴课题组 ${ }^{[29]}$ 报道了 $\mathrm{Rh}$ 催化 $\mathrm{CO}_{2} 、 \mathrm{H}_{2}$ 、 甲醇和二级胺的多组分反应制备乙酰胺的氢化还原体 系(Scheme 8). 反应需要使用 $2.6 \mathrm{~mol} \%$ 的 $\mathrm{Rh}_{2}(\mathrm{CO})_{4} \mathrm{Cl}_{2}$ 作 为催化剂, 当量的 $\mathrm{LiI}$ 和 $\mathrm{LiCl}$ 作为添加剂, $P_{\mathrm{CO}_{2}}=5 \mathrm{MPa}$, $P_{\mathrm{H}_{2}}=3 \mathrm{MPa}, 190{ }^{\circ} \mathrm{C}$ 条件下反应 $14 \mathrm{~h}$, 以较好的收率生 成乙酰胺产物. 此反应体系不需要外加配体, 可能是因 为胺类底物或者反应生成的乙酰胺产物本身可以作为 配体, 因而能够稳定催化剂加速反应的进行. 反应可能 是分步进行, 包括: (1)甲醇的羰基化生成乙酸, (2)乙酸 与胺缩合成乙酰胺. 与以往 $\mathrm{CO}_{2}$ 氢化合成甲酰胺的体系 对比，该报道实现了利用 $\mathrm{CO}_{2}$ 高效合成乙酰胺，在同一 催化体系下实现了串联反应，具有很好的兼容性.

上述的有机均相反应体系，催化剂都是过渡金属配 合物或其盐类化合物, $\mathrm{CO}_{2}$ 的氢化还原也可在酶催化的 条件下进行. 2019 年, O'Hagan 课题组 ${ }^{[30]}$ 报道了一种 $\mathrm{CO}_{2}$

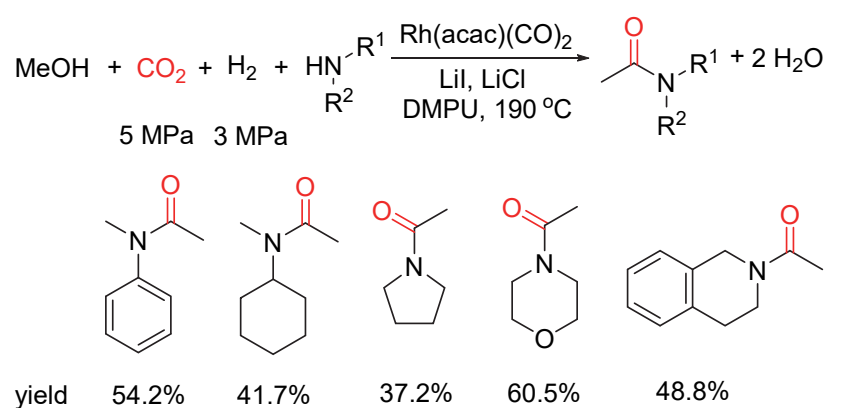

图式 $8 \mathrm{CO}_{2} 、 \mathrm{H}_{2}$ 、甲醇与二级胺反应合成乙酰胺

Scheme 8 Synthesis of acetamides using $\mathrm{CO}_{2}$, methanol, $\mathrm{H}_{2}$, and amines

氢化为甲酸的 $\mathrm{Rh}$ 催化体系, 由 $\mathrm{Rh}$ 配合物 ([Rh ${ }^{\mathrm{I}}$ $\left.\left(\mathrm{PN}^{\text {gly }} \mathrm{P}\right)_{2}\right]^{-}\left(\mathrm{PN}^{\text {gly }} \mathrm{P}=\mathrm{P}^{\mathrm{Et}_{2}}-\mathrm{CH}_{2}-\mathrm{N}^{\left(\mathrm{CH}_{2} \mathrm{CO}_{2}-\right)}-\mathrm{CH}_{2}-\mathrm{P}^{\mathrm{Et}}\right)$ 附着于 蛋白质骨架中形成的. 金属中心周围的蛋白环境可以控 制底物传送，从而提升催化活性(Scheme 9). 在溶液中, 这种 $\mathrm{Rh}$ 配合物本身没有表现出催化活性，但是当 $\mathrm{Rh}$ 配 合物与蛋白质相结合后, 可以成功实现 $\mathrm{CO}_{2}$ 的氢化反 应. 这种金属酶在室温、 $5.8 \mathrm{MPa}$ 条件下的 $\mathrm{TON}$ 为 $(14 \pm 3)$, TOF 为 $(0.38 \pm 0.03) \mathrm{h}^{-1}$. 机理研究表明, 蛋白 质骨架有效促进 $\mathrm{CO}_{2}$ 和负氢供体之间的相互作用, 因而 确保了氢化反应的顺利进行.

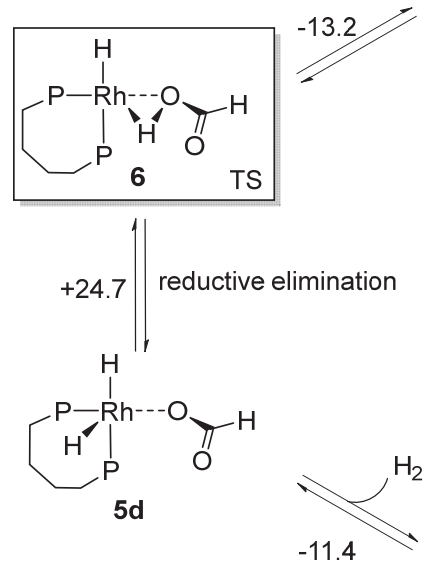<smiles>[Z7]P1CCCP[PH2]1O</smiles>
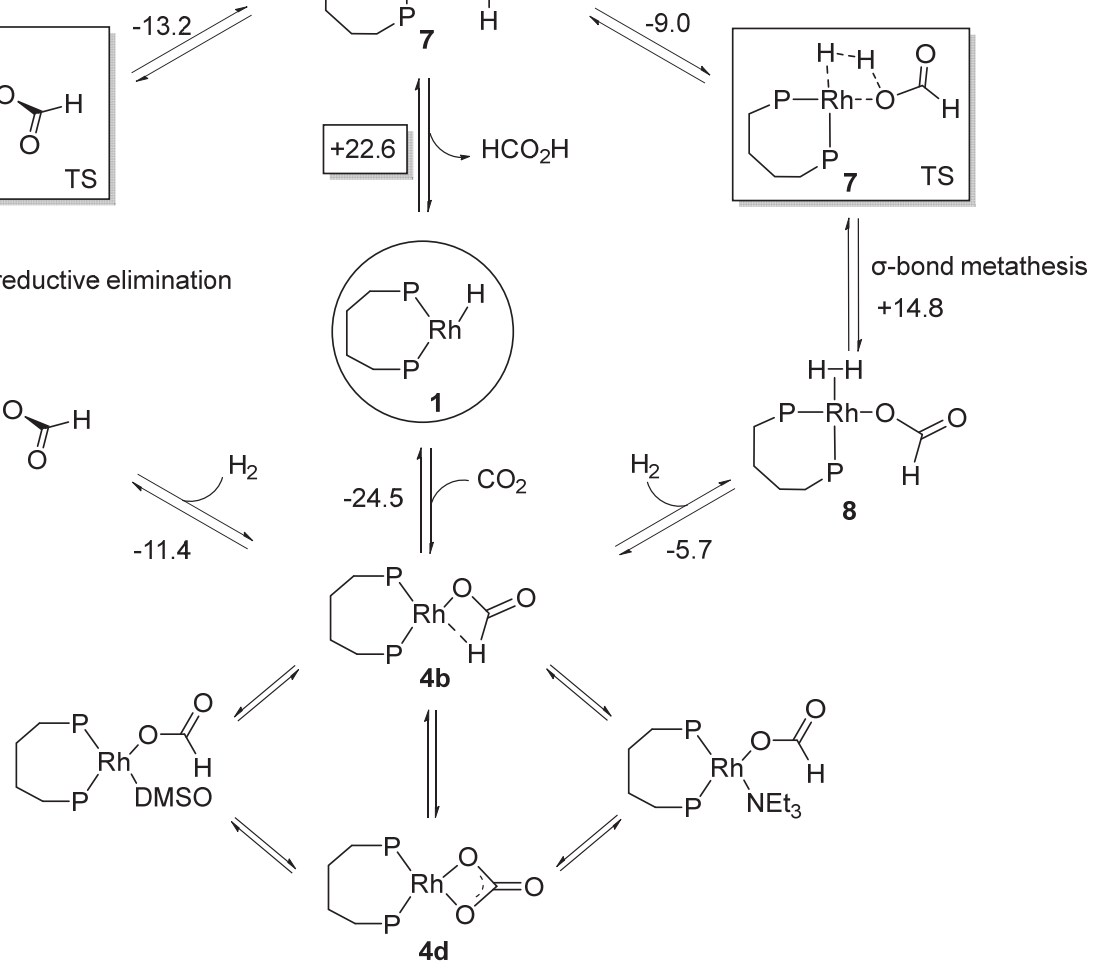

图 $2 \mathrm{Rh}$ 催化 $\mathrm{CO}_{2}$ 氢化为甲酸的理论计算

Figure 2 Theoretical calculation of the hydrogenation of $\mathrm{CO}_{2}$ catalyzed by $\mathrm{Rh}$ complex 

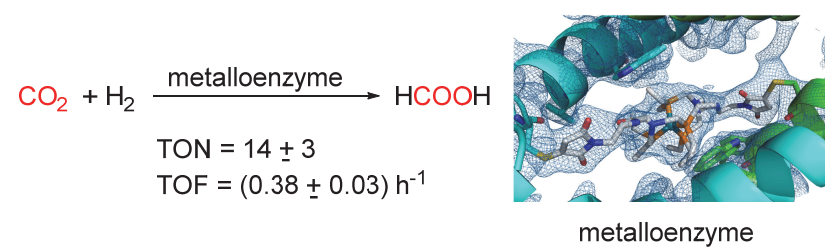

图式 9 金属酶催化 $\mathrm{CO}_{2}$ 氢化还原为甲酸

Scheme 9 Hydrogenation of $\mathrm{CO}_{2}$ to formic acid catalyzed by metalloenzymes

\subsubsection{Ir 催化体系}

除了 $\mathrm{Ru}$ 和 $\mathrm{Rh}$ 催化剂以外, Ir、Pd 和 $\mathrm{Pt}$ 催化剂也常 用于 $\mathrm{CO}_{2}$ 氢化反应合成甲酸及其衍生物. 2005 年, Himeda 课题组 ${ }^{[34]}$ 将 4,7-二羟基-1,10-菲啰啉的 $\mathrm{Ru}(\mathrm{II})$, $\operatorname{Rh}(\mathrm{III})$ 和 $\mathrm{Ir}(\mathrm{III})$ 配合物用于碳酸氢盐的氢化合成甲酸盐, 这些催化剂在 $\mathrm{KOH}$ 溶液中展现出优异的催化氢化活性 (Scheme 10). 其中 $\operatorname{Ir}(\mathrm{III})$ 配合物的活性最高, 在 $120{ }^{\circ} \mathrm{C}$ 和 $3.0 \mathrm{MPa} \mathrm{H}$ 条件下, 具有较高的收率, $\mathrm{TON}$ 为 21000 , TOF 为 $23000 \mathrm{~h}^{-1}$. 值得一提的是, 配体上的羟基在碱的 作用下脱去质子产生的氧负离子, 具有强的供电子能 力; 并且, 还可以增加配合物的水溶性, 因而可以提高
催化活性. 通过条件优化能大幅度提高催化活性 ${ }^{[35]}$, 最 高 $\mathrm{TON}$ 可达 $1.9 \times 10^{5}$, TOF 为 $4.2 \times 10^{4} \mathrm{~h}^{-1}$.

Ir 催化 $\mathrm{CO}_{2}$ 氢化在酸性水溶液中同样可以进行. 2006 年, Fukuzumi 课题组 ${ }^{[36]}$ 采用 $\left[\left(\eta^{6}-\mathrm{C}_{6} \mathrm{Me}_{6}\right) \mathrm{Ru}^{\mathrm{II}}(\mathrm{L})-\right.$ $\left.\left(\mathrm{OH}_{2}\right)\right]^{2+}$ 和 $\left[\mathrm{Cp}^{*} \mathrm{Ir}^{\mathrm{III}}(\mathrm{L})\left(\mathrm{OH}_{2}\right)\right]^{2+}$ 催化剂实现了在 $\mathrm{pH}$ 为 3 的酸性水溶液中将 $\mathrm{CO}_{2}$ 氢化为甲酸(图 3). 反应中涉及 的关键 $\mathrm{M}-\mathrm{H}$ 中间体在酸性条件下是不稳定的, 所以对 于在水溶液中氢化反应，需要加入大量的碱(如 $\mathrm{KOH}$ ), 以获得相应的甲酸盐(如 HCOOK). 此外, 加入碱能中 和甲酸, 在热力学上是有利的. 而且, 成功地分离表征 了关键活性负氢中间体 $\left[\mathrm{Cp}^{*} \operatorname{Ir}^{\mathrm{III}}(\mathrm{L})(\mathrm{H})\right]^{+}$, 进一步通过动 力学研究验证了活性负氢中间体的作用.

上述的报道中使用的配体都是菲啰啉和联吡啶双 齿氮配体，对于 Pincer 以及咪唑配体也有相关的报道. 2009 年, Nozaki 等 ${ }^{[37]}$ 报道了一种 Ir $^{\mathrm{III} / \mathrm{PNP}}$ 型配合物在 $\mathrm{KOH}$ 水溶液中 $\mathrm{CO}_{2}$ 氢化生成甲酸盐的体系. 当使用 Ir/pincer 催化剂, 反应温度在 $200{ }^{\circ} \mathrm{C}, P_{\mathrm{CO}_{2}}=P_{\mathrm{H}_{2}}=2.5$ $\mathrm{MPa}$ 条件下反应 $2 \mathrm{~h}$, 最高 $\mathrm{TOF}=1.5 \times 10^{5} \mathrm{~h}^{-1}$ (Scheme 11). 在 $120{ }^{\circ} \mathrm{C}, P_{\mathrm{CO}_{2}}=P_{\mathrm{H}_{2}}=3 \mathrm{MPa}$ 条件下反应 $48 \mathrm{~h}$, 以

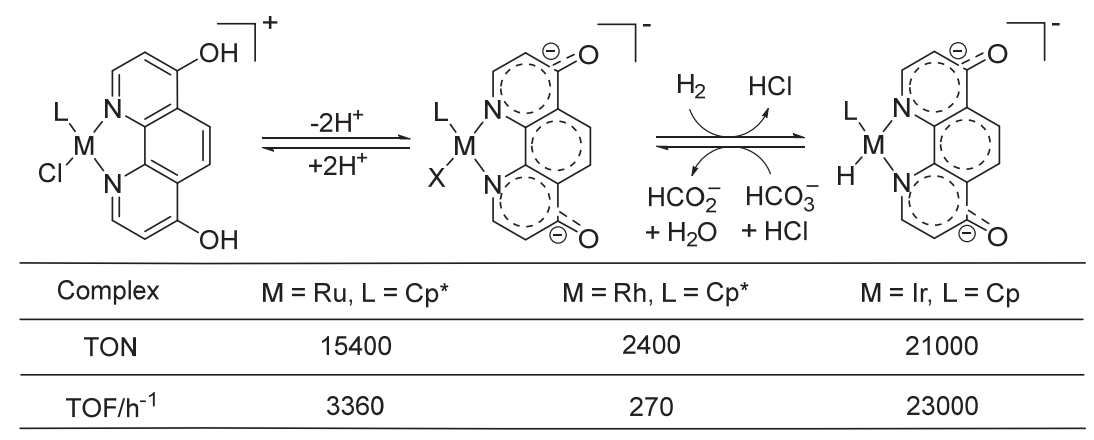

图式 10 菲啰啉骨架螯合的 Ru、Rh、Ir 配合物用于氢化碳酸盐合成甲酸盐

Scheme $10 \mathrm{Ru}(\mathrm{II}), \mathrm{Rh}(\mathrm{III})$, and $\mathrm{Ir}(\mathrm{III})$ complexes with phenanthroline ligand for the hydrogenation of bicarbonate to formate

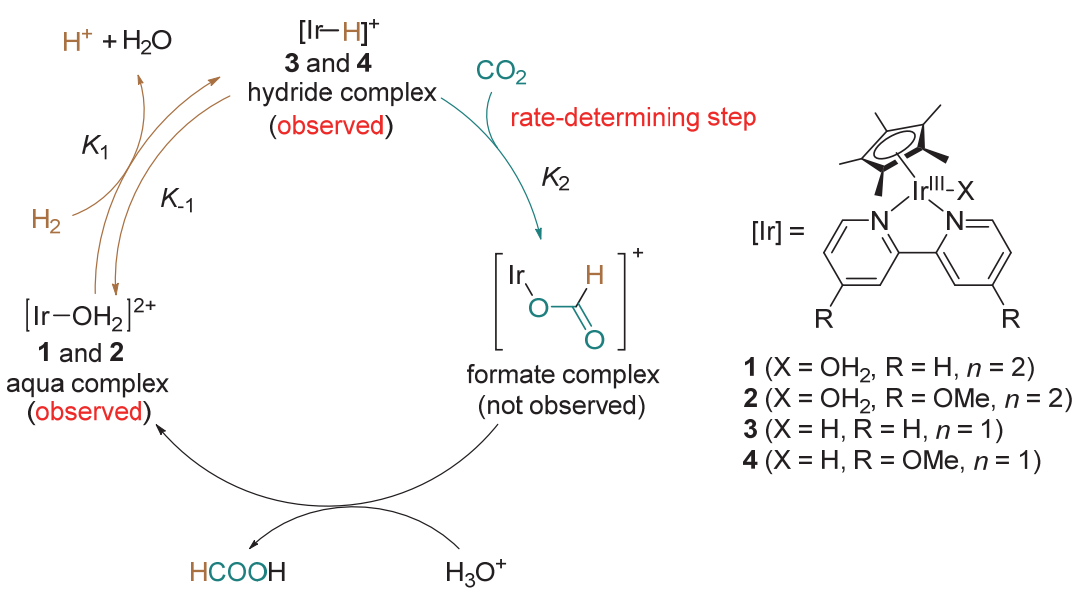

图 3 联吡啶 $\mathrm{Ir}^{\mathrm{III}}$ 配合物用于 $\mathrm{CO}_{2}$ 氢化为甲酸

Figure 3 Hydrogenation of $\mathrm{CO}_{2}$ to formic acid with bipyridine $\mathrm{Ir}^{\mathrm{III}}$ complex 


$$
\mathrm{H}_{2}+\mathrm{CO}_{2}+1 \mathrm{~mol} / \mathrm{L} \mathrm{KOH} \frac{\mathrm{Ir}^{\mathrm{III}} \text { complex }}{\mathrm{THF}} \mathrm{HCOOK}
$$
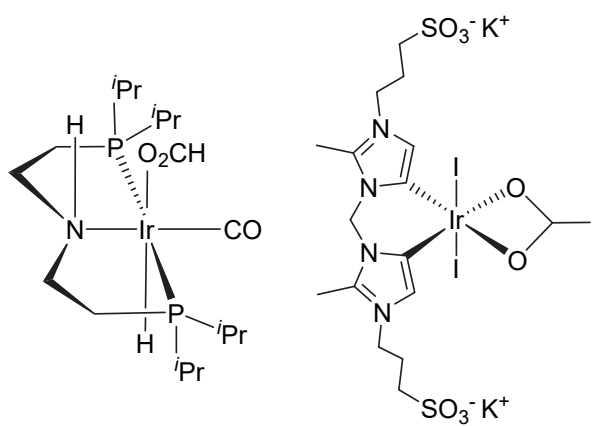

图式 $11 \mathrm{Ir}{ }^{\mathrm{III}} / \mathrm{PNP}$ 和 $\mathrm{Ir}{ }^{\mathrm{III}} / \mathrm{NHC}$ 配合物用于 $\mathrm{CO}_{2}$ 氢化还原为甲 酸盐

Scheme 11 Hydrogenation of $\mathrm{CO}_{2}$ to formate with $\mathrm{Ir}^{\mathrm{III}} / \mathrm{PNP}$ and Ir III/NHC complex

$70 \%$ 的收率实现了 $\mathrm{CO}_{2}$ 的氢化反应, 最高 $\mathrm{TON}=$ 3500000 , 生成甲酸盐的浓度可达到 $0.7 \mathrm{~mol} / \mathrm{L} .2011$ 年, Hazari 课题组 ${ }^{[38]}$ 发展了 $\mathrm{Ir}^{\mathrm{III}}$ 配合物催化 $\mathrm{CO}_{2}$ 氢化为甲酸 盐的体系, 并证实了在第二配位层中使用氢键给体可以 促进 $\mathrm{CO}_{2}$ 插入到 $\mathrm{Ir}-\mathrm{H}$ 键中生成活性中间体, 该水溶性 的中间体可作为 $\mathrm{CO}_{2}$ 氢化的活性催化剂. 氢化反应在极 少量的 $\mathrm{Ir}$ 催化剂作用下实现 $\mathrm{CO}_{2}$ 的氢化, $\mathrm{TON}$ 最高达到 348000 , 最高 TOF 达到 $14500 \mathrm{~h}^{-1}$. 同年, Peris 课题组 ${ }^{[39]}$ 报道了侧链含有磺酸取代基的氮杂环卡宾配体的 $\mathrm{Ir}^{\mathrm{III}}$ 络 合物 $\left[\operatorname{IrI}_{2}(\mathrm{AcO})(\right.$ bis-NHC) $]$, 最高 TON 可达 $1.9 \times 10^{5}$. 此 外, 以 $i-\mathrm{PrOH}$ 为氢源, 该配合物催化 $\mathrm{CO}_{2}$ 氢化的 $\mathrm{TON}$ 最高达 2700 .

周其林课题组 ${ }^{[40]}$ 发展了新型含有亚胺结构的 Pincer Ir 催化剂, 对于 $\mathrm{CO}_{2}$ 氢化还原为甲酸盐, 收率达到 $99 \%$, TON 高达 450000 (Scheme 12). 研究表明, 配体中的亚 胺基团在异裂 $\mathrm{H}_{2}$ 以及活化 $\mathrm{CO}_{2}$ 的过程中起到了重要作 用，亚胺结构的引入能够加速氢化反应的氢转移.

Espino 课题组 ${ }^{[41]}$ 报道了一类 $\mathrm{Ru}$ 配合物 [( $p$-cymene)$\left.\mathrm{RuCl}\left(\mathrm{N}, \mathrm{N}^{\prime}\right)\right] \mathrm{X}\left(\mathrm{X}=\mathrm{Cl}^{-} 、 \mathrm{BF}_{4}^{-}\right), \mathrm{Rh}$ 和 $\mathrm{Ir}$ 的配合物 $\left[\mathrm{Cp} * \mathrm{MCl}\left(\mathrm{N}, \mathrm{N}^{\prime}\right)\right] \mathrm{Cl}(\mathrm{M}=\mathrm{Rh}, \mathrm{Ir})$ 用于在碱性溶液中 $\mathrm{CO}_{2}$ 的 氢化，最高 TON 可达 6021 (Scheme 13).

Fujita 课题组 ${ }^{[42]}$ 报道了酰胺基配位的 Ir 配合物用于 $\mathrm{CO}_{2}$ 氢化还原为甲酸盐(Scheme 14), 通过研究氮原子上 不同取代基的电子效应对于氢化反应活性产生的影响, 发现氮原子上供电子基团有利于提高活性. 吡啶基团邻 位的着基以及酰胺基团与 Ir 配位, 稳定催化剂并促进氢 化反应. 因此, 反应室温 $50{ }^{\circ} \mathrm{C}$ 下, $\mathrm{H}_{2} / \mathrm{CO}_{2}(V: V=1: 1$, $0.1 \mathrm{MPa}$ )条件下即可发生氢化反应.

\section{2 丰产金属催化体系}

贵金属催化剂可高效地催化 $\mathrm{CO}_{2}$ 氢化反应制备甲 酸及甲酸盐、甲酸酯、甲酰胺等产物. 相关的基础研究

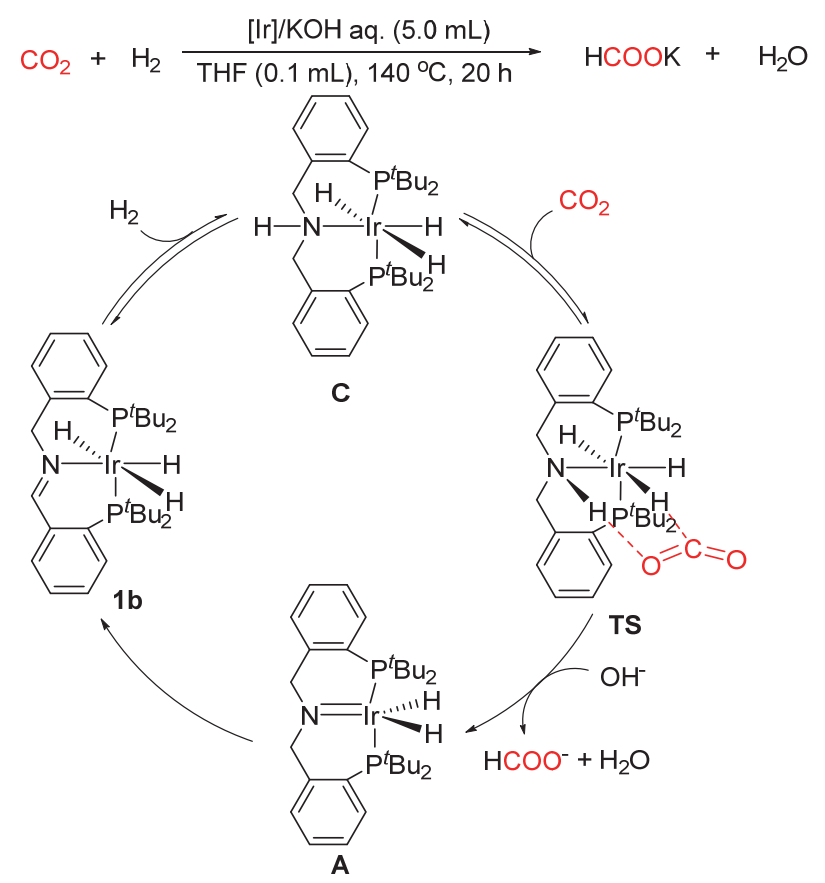

图式 $12 \mathrm{Ir} / \mathrm{PNP}$ 催化 $\mathrm{CO}_{2}$ 氢化合成甲酸盐

Scheme 12 Hydrogenation of $\mathrm{CO}_{2}$ to formate catalyzed by Ir/PNP complex

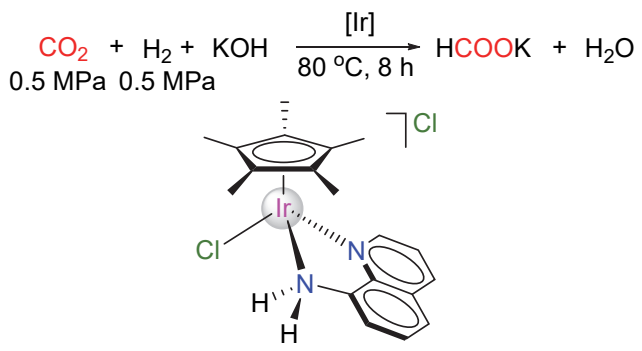

图式 $13 \mathrm{Ir}$ 催化 $\mathrm{CO}_{2}$ 氢化合成甲酸盐

Scheme 13 Hydrogenation of $\mathrm{CO}_{2}$ to formate catalyzed by Ir(III) complex

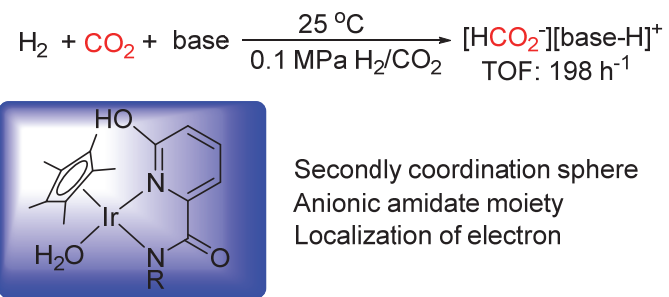

图式 14 酰胺螯合的 $\mathrm{Ir}$ 配合物催化 $\mathrm{CO}_{2}$ 氢化 Scheme $14 \mathrm{CO}_{2}$ hydrogenation using Ir catalysts with amide-based ligands

已经实现了工业化放大，例如丁奎岭等开发的 $\mathrm{Ru} / \mathrm{PNP}$ 催化体系对于 $\mathrm{CO}_{2}$ 氢化还原为 $\mathrm{DMF}$ 已经完成了中试放 大. 但是，由于贵金属催化剂价格昂贵，而研究丰产金 属配合物催化 $\mathrm{CO}_{2}$ 氢化还原为甲酸及其衍生物具有较 大的发展空间和市场需求．对于廉价金属催化剂用于 
$\mathrm{CO}_{2}$ 的氢化反应而言, 使用最多的金属是 $\mathrm{Fe} 、 \mathrm{Co} 、 \mathrm{Ni}$ 催化剂. 我们将丰产金属催化 $\mathrm{CO}_{2}$ 氢化的代表性工作列 入表 3 .

早在 1978 年, Evans 和 Newell ${ }^{[45]}$ 使用 $\left[\mathrm{N}\left(\mathrm{PPh}_{3}\right)_{2}\right]$ $\left[\mathrm{HFe}_{3}(\mathrm{CO})_{11}\right.$ 和 $\left[\mathrm{HN}\left(\mathrm{C}_{2} \mathrm{H}_{5}\right)_{3}\right]\left[\mathrm{HFe}_{3}(\mathrm{CO})_{11}\right]$ 作为催化剂实 现 $\mathrm{CO}_{2}$ 的氢化反应, 随后与醇缩合生成甲酸酯的反应. 但是体系的反应条件较为苛刻, 时间较长, 且反应效率 较低 $\left(\mathrm{TON}=6, \mathrm{TOF}=0.06 \mathrm{~h}^{-1}\right) .2003$ 年, Jessop 课题 组 ${ }^{[46]}$ 通过高通量篎选, 发现 $\mathrm{Fe}(\mathrm{OAc})_{2}$ 或者 $\mathrm{FeCl}_{3}$ 与双齿 膦配体形成的活性催化剂可较为有效地催化 $\mathrm{CO}_{2}$ 的氢 化反应。通过条件篮选, $\mathrm{FeCl}_{3} / 1,2$-双二苯基膦乙烷 (dppe)催化体系可获得最高的转化数 $\mathrm{TON}=113.2010$ 年, Beller 等 ${ }^{[47]}$ 报道了 $\left[\mathrm{FeH}\left(\mathrm{PP}_{3}\right)\right] \mathrm{BF}_{4}$ 催化剂既能用于 $\mathrm{CO}_{2}$ 的氢化, 也可将碳酸氢盐氢化制备甲酸、甲酰胺或 者甲酸酯. 关键在于使用四齿膦配体与 $\mathrm{Fe}\left(\mathrm{BF}_{4}\right)_{2}$ ・ $6 \mathrm{H}_{2} \mathrm{O}$ 生成活性 $\mathrm{Fe}$ 催化剂 $\left[\mathrm{FeH}\left(\mathrm{H}_{2}\right)\left(\mathrm{PP}_{3}\right)\right] \mathrm{BF}_{4}($ Scheme 15 ). 该类活性 $\mathrm{Fe}$ 催化剂可以将碳酸氢盐还原至甲酸盐 的最高 $\mathrm{TON}=624, \mathrm{CO}_{2}$ 氢化生成甲酸甲酯的最高 $\mathrm{TON}=585$, 生成甲酰胺的最高 $\mathrm{TON}=727$. 这些结果反 映了四齿膦配体 Fe 配合物的结构优异性.

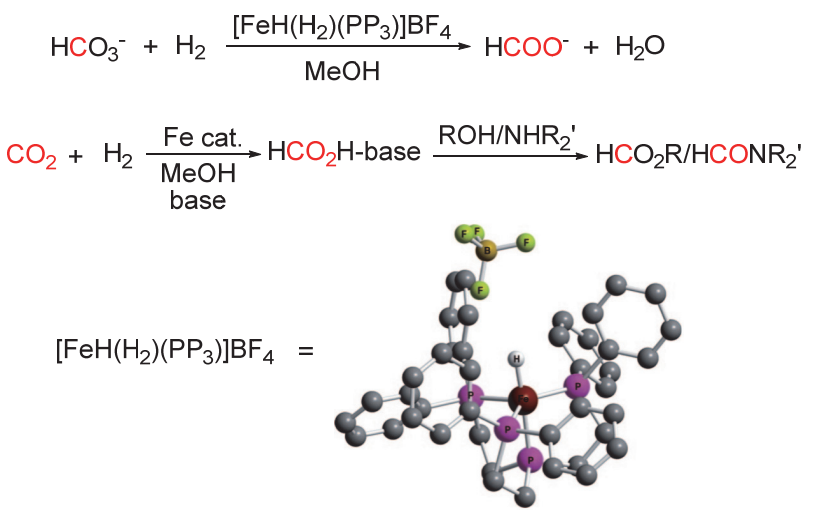

图式 $15\left[\mathrm{FeH}\left(\mathrm{H}_{2}\right)\left(\mathrm{PP}_{3}\right)\right] \mathrm{BF}_{4}$ 催化 $\mathrm{CO}_{2} /$ 碳酸氢盐的氢化反应 Scheme 15 Hydrogenation of $\mathrm{CO}_{2} /$ bicarbonate catalyzed with $\left[\mathrm{FeH}\left(\mathrm{H}_{2}\right)\left(\mathrm{PP}_{3}\right)\right] \mathrm{BF}_{4}$

2012 年, Beller 课题组 ${ }^{[48]}$ 在上述 $\mathrm{Fe}$ 配合物的基础上 进行适当的结构改造, 将催化剂结构中的 $\mathrm{Fe}-\mathrm{H}$ 键替换 为 $\mathrm{Fe}-\mathrm{F}$ 键, 改造后的催化剂对于 $\mathrm{CO}_{2}$ 和碳酸氢盐的氢 化具有更高的催化活性(Scheme 16), 尤其对碳酸氢盐 显示出更高的收率, 同时 $\mathrm{TON}>7500, \mathrm{TOF}>750 \mathrm{~h}^{-1}$, 通过机理实验证实 $\mathrm{Fe}-\mathrm{H}-\mathrm{H}_{2}$ 中间体在反应中起决定性作 用.

除了上述两例四齿膦配体用于 $\mathrm{CO}_{2}$ 的氢化以外, Laurenczy 课题组 ${ }^{[49]}$ 使用间三磺酸钠-三(2-(二苯基膦)乙基)膦( $\mathrm{PP}_{3} \mathrm{TS}$ )配体配位的 $\mathrm{Fe}(\mathrm{II})$ 催化剂用于水溶液中 $\mathrm{CO}_{2}$ 氢化为甲酸的报道. 在此均相反应中, 无需任何添

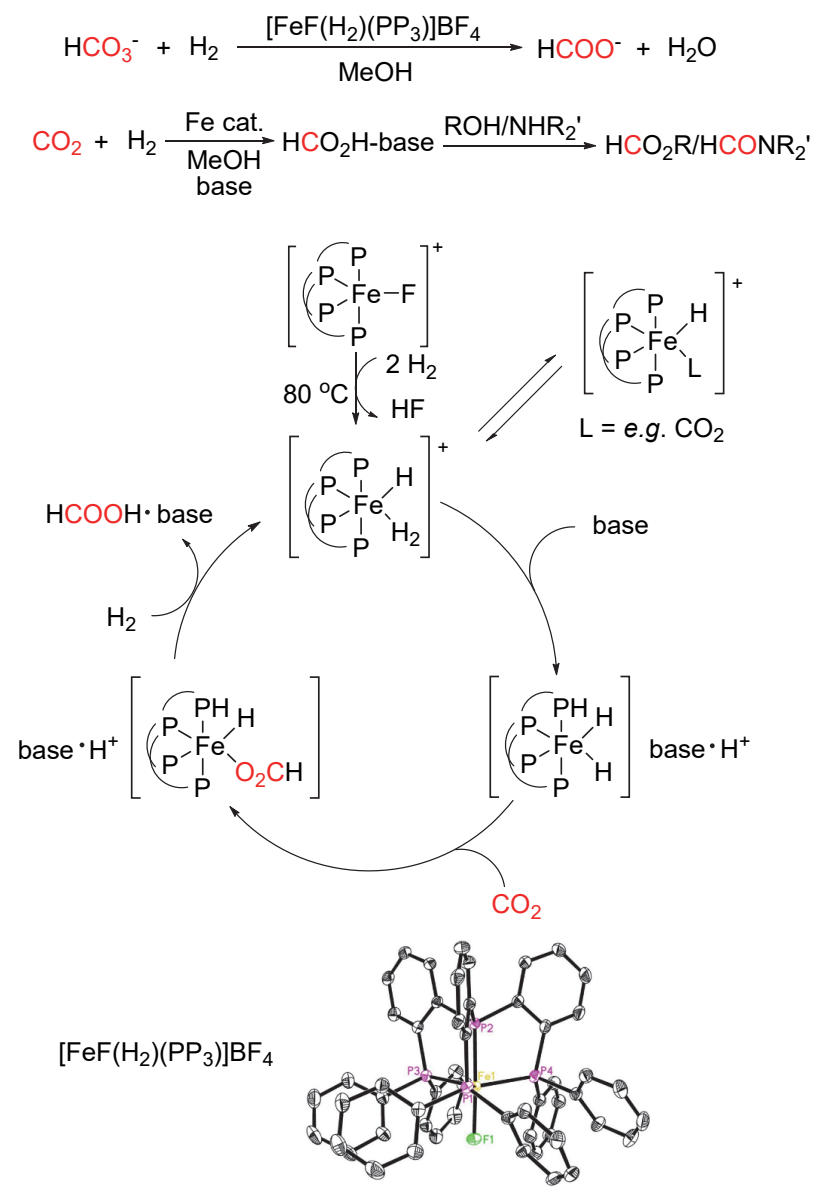

图式 $16\left[\mathrm{FeF}\left(\mathrm{H}_{2}\right)\left(\mathrm{PP}_{3}\right)\right] \mathrm{BF}_{4}$ 催化 $\mathrm{CO}_{2} /$ 碳酸氢盐的氢化反应 Scheme 16 Hydrogenation of $\mathrm{CO}_{2} /$ bicarbonate catalyzed with $\left[\mathrm{FeF}\left(\mathrm{H}_{2}\right)\left(\mathrm{PP}_{3}\right)\right] \mathrm{BF}_{4}$

加剂室温下实现 $\mathrm{CO}_{2}$ 的氢化反应，可能是因为配体中的 磺酸根基团既能增强催化剂的水溶性，还具有一定的碱 性，从而能够促进反应(Scheme 17).

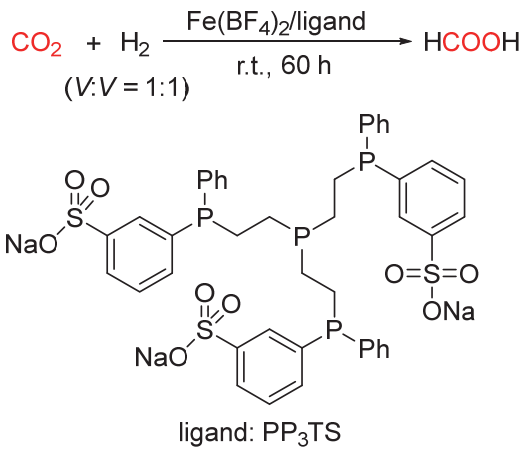

图式 $17 \mathrm{Fe}^{\mathrm{II}} / \mathrm{PP}_{3} \mathrm{TS}$ 体系在水相中催化 $\mathrm{CO}_{2}$ 氢化生成甲酸 Scheme 17 Hydrogenation of $\mathrm{CO}_{2}$ to formic acid catalyzed with $\mathrm{Fe}$ II/PNP system in aqueous phase

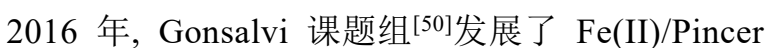
(2,6-二亚胺吡啶骨架)配合物催化剂，该催化剂在碱性 条件下的质子性溶剂中可将 $\mathrm{CO}_{2}$ 和碳酸氢钠氢化为甲 
表 $3 \mathrm{CO}_{2} /$ 碳酸氢盐的催化氢化代表性体系

Table 3 Selected catalytic systems for the hydrogenation of $\mathrm{CO}_{2} /$ bicarbonate

\begin{tabular}{|c|c|c|c|c|c|c|c|c|}
\hline Catalyst precursor & Solvent & Additive & $P\left(\mathrm{CO}_{2} / \mathrm{H}_{2}\right) / \mathrm{MPa}$ & $T /{ }^{\circ} \mathrm{C}$ & Time/h & TON & $\mathrm{TOF} /\left(\mathrm{h}^{-1}\right)$ & Ref. \\
\hline $\mathrm{Fe}\left(\mathrm{BF}_{4}\right)_{2} \cdot 6 \mathrm{H}_{2} \mathrm{O} / \mathrm{PP}_{3}$ & $\mathrm{MeOH}$ & $\mathrm{NaHCO}_{3}$ & $0 / 6.0$ & 100 & 20 & 7546 & 377 & [48] \\
\hline$\left[(\mathrm{PNP}) \mathrm{Fe}\left(\mathrm{H}_{2}\right)(\mathrm{CO})\right]$ & $\mathrm{H}_{2} \mathrm{O} / \mathrm{THF}$ & $\mathrm{NaOH}$ & $0.33 / 0.67$ & 80 & 5 & 790 & 160 & [60] \\
\hline$[(\mathrm{PNNNP}) \mathrm{Fe}(\mathrm{H}) \mathrm{Br}(\mathrm{CO})]$ & EtOH & DBU & $4.0 / 4.0$ & 80 & 21 & 10275 & 489 & [50] \\
\hline$[(\mathrm{PNP}) \mathrm{Fe}(\mathrm{H})(\mathrm{OOCH})(\mathrm{CO})]$ & THF & DBU/LiOTf & $3.5 / 3.5$ & 80 & 1 & 46100 & 23200 & [61] \\
\hline$\left[\mathrm{Fe}\left(\mathrm{rac}-\mathrm{P}_{4}\right)\left(\mathrm{CH}_{3} \mathrm{CN}\right)_{2}\right]\left(\mathrm{BF}_{4}\right)_{2}$ & $\mathrm{MeOH}$ & $\mathrm{NaHCO}_{3}$ & $0 / 6.0$ & 80 & 24 & 1200 & 50 & {$[62]$} \\
\hline$[\mathrm{Fe}]$ complex & $\mathrm{EtOH} / \mathrm{H}_{2} \mathrm{O}$ & $\mathrm{NaHCO}_{3}$ & $0 / 3.0$ & 120 & 24 & 447 & 19 & [63] \\
\hline $\mathrm{Co}\left(\mathrm{BF}_{4}\right)_{2} \cdot 6 \mathrm{H}_{2} \mathrm{O} / \mathrm{PP}_{3}$ & $\mathrm{MeOH}$ & $\mathrm{NaHCO}_{3}$ & $0 / 6.0$ & 120 & 20 & 3877 & 190 & [64] \\
\hline$\left[\mathrm{Co}(\mathrm{DMPE})_{2} \mathrm{H}\right]$ & THF & Verkade's base & $1.0 / 1.0$ & 21 & $\mathrm{n} / \mathrm{a}$ & 9400 & 74000 & [65] \\
\hline$\left[\mathrm{Cp}^{*} \mathrm{Co}\left(4,4^{\prime}-\mathrm{DHBP}\right)\left(\mathrm{H}_{2} \mathrm{O}\right)\right]\left(\mathrm{PF}_{6}\right)_{2}$ & $\mathrm{H}_{2} \mathrm{O}$ & $\mathrm{NaHCO}_{3}$ & $2.0 / 2.0$ & 100 & 1 & 39 & 39 & [66] \\
\hline$\left[\left(\mathrm{PNP}_{5}\right)_{\mathrm{Co}}(\mathrm{CO})_{2}\right] \mathrm{Cl}$ & $\mathrm{CH}_{3} \mathrm{CN}$ & DBU/LiOTf & $3.5 / 3.5$ & 45 & 1 & 29000 & 5700 & [67] \\
\hline$[(\mathrm{PCP}) \mathrm{Ni}(\mathrm{H})]) \mathrm{RuH}(\mathrm{CO})]$ & $\mathrm{MeOH}$ & $\mathrm{NaHCO}_{3}$ & $0 / 5.5$ & 150 & 20 & 3000 & 150 & [68] \\
\hline $\mathrm{Cu}(\mathrm{OAc})_{2} \cdot \mathrm{H}_{2} \mathrm{O}$ & 1,4-Dioxane & DBU & $2.0 / 2.0$ & 100 & 116 & 167 & 1.4 & [56] \\
\hline$[\mathrm{Cu}($ triphos $)(\mathrm{MeCN})] \mathrm{PF}_{6}$ & $\mathrm{CH}_{3} \mathrm{CN}$ & DBU & $2.0 / 2.0$ & 140 & 2 & 96 & 48 & [57] \\
\hline$\left[\left(\mathrm{PMeNP}_{4}\right) \mathrm{Mo}\left(\mathrm{C}_{2} \mathrm{H}_{4}\right)(\mathrm{OOCH})\right]$ & 1,4-Dioxane & DBU/LiOTf & $3.5 / 3.5$ & 100 & 16 & 35 & 2 & [69] \\
\hline
\end{tabular}

酸盐, 具有定量的收率(图 4). 还原 $\mathrm{CO}_{2}$ 为甲酸盐最高 TON 可达 10275; 对于 $\mathrm{NaHCO}_{3}$ 还原为 $\mathrm{HCO}_{2} \mathrm{Na}$ 最高 TON 可达 4560. 此外, 质子性溶剂可以稳定反应的中间 体，协助甲酸产物脱离金属中心，从而促进反应.

2018 年, Bernskoetter 课题组 ${ }^{[51]}$ 报道了铁 Pincer 配合 物催化的 $\mathrm{CO}_{2}$ 氢化反应合成甲酰胺(Scheme 18). Pincer 配体的氢化效率明显高于二级胺骨架, 说明含有 $\mathrm{N}-\mathrm{H}$ 键的双功能型二级胺对于氢化反应没有促进作用. 含有 叔胺结构的 $\mathrm{Fe}(\mathrm{II}) / \mathrm{PNP}$ 催化剂对于 $\mathrm{CO}_{2}$ 氢化具有很好的 底物普适性, 最高收率为 $92 \%$, 最高 TON 可达 8900 . 机 理研究表明, 反应是 $\mathrm{CO}_{2}$ 先经过氢化生成甲酸胺盐, 随 后经过脱水生成甲酰胺.

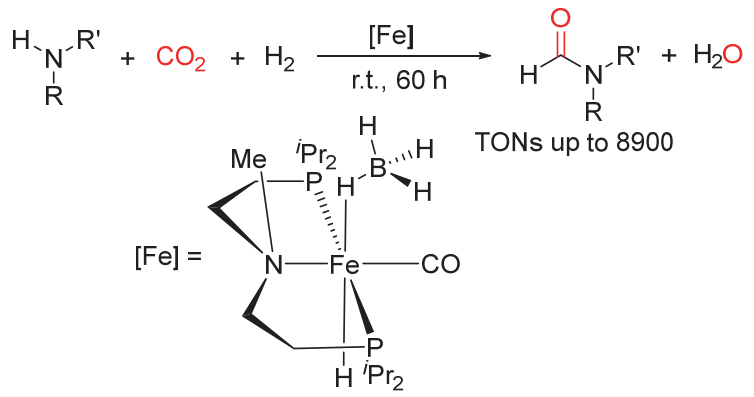

图式 $18 \mathrm{Fe}$ II/Pincer 体系催化 $\mathrm{CO}_{2}$ 氢化合成甲酰胺 Scheme 18 Hydrogenation of $\mathrm{CO}_{2}$ to formamide catalyzed with $\mathrm{Fe}^{\mathrm{II} / \text { Pincer system }}$

丰产金属 $\mathrm{Co}$ 也可以用于 $\mathrm{CO}_{2}$ 的氢化还原 ${ }^{[52]} .2012$ 年, Beller 课题组 ${ }^{[52 b]}$ 发展了 $\left[\mathrm{Co}(\mathrm{H}) \mathrm{PPh}_{3}\right]$ 催化剂在碱性条 件下催化 $\mathrm{CO}_{2}$ 氢化为甲酸盐、甲酸酯和甲酰胺的体系. 产物收率可达 $74 \%$, 最高 TON 为 3877 . 相比于其他的 廉价金属而言, 这类 $\mathrm{Co}$ 配合物催化 $\mathrm{CO}_{2}$ 氢化为甲酸的 效率要明显高于 $\mathrm{Fe}$ 催化剂. 对于 $\mathrm{Ni}$ 催化剂而言, 2003 年, Jessop 课题组 ${ }^{[53]}$ 报道了使用 $\mathrm{NiCl}_{2}$ 和双膦配体原位生
成的 $\mathrm{Ni}$ 配合物，对于 $\mathrm{CO}_{2}$ 氢化为甲酸盐的 $\mathrm{TON}$ 为 117 , $\mathrm{TOF}=15.6 \mathrm{~h}^{-1}$. 通过使用 $\mathrm{NiCl}_{2}$ (dcpe)催化剂, 延长反应 时间, 可将 TON 提高到 4400. 近来, 将原位产生的 $\mathrm{MX}_{2} / \mathrm{dmpe}$ 催化剂用于 $\mathrm{CO}_{2}$ 氢化合成甲酰胺. 当使用吗 啉作为碱时, 甲酰吗啉的收率可以达到 $90 \%, \mathrm{TON}=$

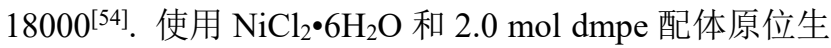
成 $\mathrm{NiCl}_{2}\left(\mathrm{dmpe}\right.$ ) 催化剂, 对于 $\mathrm{CO}_{2}$ 氢化合成 $\mathrm{DMF}$ 展现出 了中等的收率, 最高 TON 可达 $6300^{[55]}$.

对于 $\mathrm{Cu}$ 配合物, 研究其对于 $\mathrm{CO}_{2}$ 氢化反应的报道 较少. 2015 年, Ikariya 课题组 ${ }^{[56]}$ 报道了 $\mathrm{Cu}(\mathrm{OAc})_{2} \cdot \mathrm{H}_{2} \mathrm{O}$ 在 碱性条件下 $\mathrm{CO}_{2}$ 氢化的例子(Scheme 19). 体系无需额外 加入配体, 在相对温和的条件下 $P_{\mathrm{CO}_{2}}=P_{\mathrm{H}_{2}}=2.0 \mathrm{MPa}$, $100{ }^{\circ} \mathrm{C}$ 下反应 $116 \mathrm{~h}$, 收率为 $33 \%$, TON 可以达到 167 . 同年, Appel 课题组 ${ }^{[57]}$ 报道了 $[\mathrm{Cu}($ triphos $)(\mathrm{MeCN})] \mathrm{PF}_{6}$ 在 含有 $\mathrm{DBU}$ 的乙腈溶液中 $\mathrm{CO}_{2}$ 的氢化生成甲酸盐, 最高 TON 可达 $500, \mathrm{TOF}$ 为 $25 \mathrm{~h}^{-1}$.

此外, 胆碱咪唑离子液体 $(\mathrm{Ch}-\mathrm{ILs}) / \mathrm{CuCl}$ 体系可有效 催化 $\mathrm{CO}_{2}$ 氢化合成甲酰胺 ${ }^{[58]} .1 \mathrm{~mol}$ 胆碱咪唑离子液体 可以吸收 $1.17 \mathrm{~mol} \mathrm{CO}_{2}$, 经活化的 $\mathrm{CO}_{2}$ 可以在 $\mathrm{CuCl}$ 的作 用下与各种胺类生成甲酰胺，收率 $31 \% \sim 99 \%$. 此外， $\mathrm{Zn}$ 催化剂在硅烷条件下可以实现 $\mathrm{CO}_{2}$ 与胺类发生氢甲 酰化以及嫝化反应 ${ }^{[59]}$.

\section{2 四电子氢化产物}

$\mathrm{CO}_{2}$ 可以通过催化加氢制备甲醛类产物, 此过程中 $\mathrm{CO}_{2}$ 经历了四电子还原. 用 2 equiv. $\mathrm{H}_{2}$ 将 $\mathrm{CO}_{2}$ 还原为甲 醛, 同时生成一分子的 $\mathrm{H}_{2} \mathrm{O}$. 甲醛属于大宗化学品, 全 球年生产量超过 2000 万吨, 在建筑行业, 木材加工行 业、家具制造业以及纺织业具有广泛的用途 ${ }^{[70]}$. 工业上， 甲醛是通过甲醇的催化氧化制备的，通常以改性的 

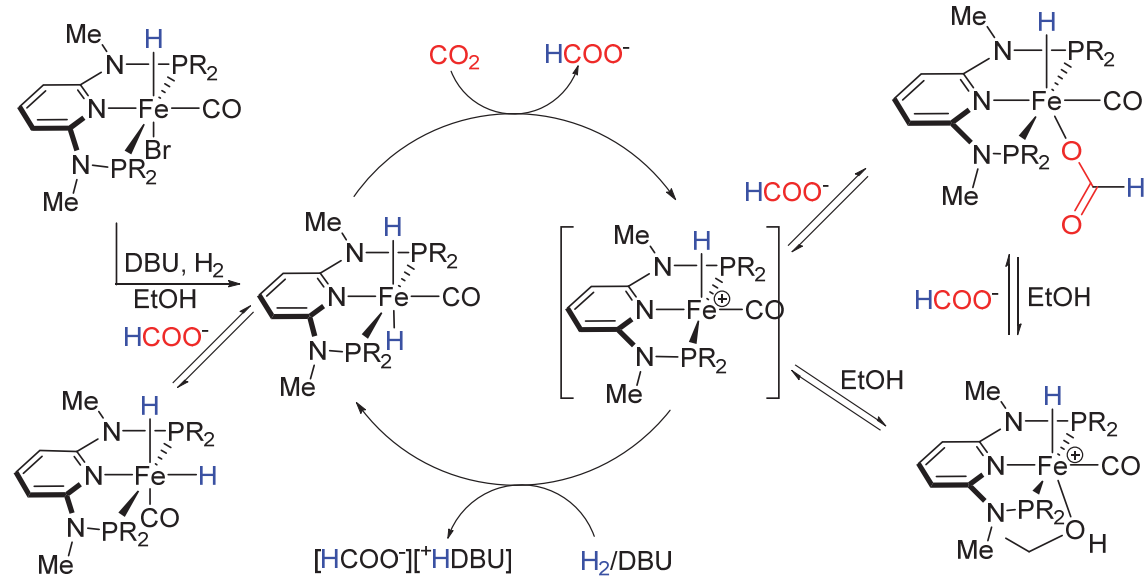

HCOO- $\mid$ EtOH

图 $4 \mathrm{Fe} / \mathrm{PNP}$ 催化 $\mathrm{CO}_{2}$ 氢化生成甲酸盐

Figure 4 Hydrogenation of $\mathrm{CO}_{2}$ into formate catalyzed by $\left[\mathrm{FeF}\left(\mathrm{H}_{2}\right)\left(\mathrm{PP}_{3}\right)\right] \mathrm{BF}_{4}$

$$
\begin{array}{rl}
\mathrm{CO}_{2}+\mathrm{H}_{2}+\mathrm{DBU} \frac{\mathrm{Cu}(\mathrm{OAC})_{2} \cdot \mathrm{H}_{2} \mathrm{O}}{1,4 \text {-dioxane, } 100{ }^{\circ} \mathrm{C}} & {\left[\mathrm{HCO}_{2}\right]^{-}[\mathrm{DBU}-\mathrm{H}]^{+}} \\
\mathrm{CO}_{2}, \mathrm{H}_{2}=2 \sim 4 \mathrm{MPa} & \text { TONs up to } 167 \\
\mathrm{DBU} / \mathrm{Cu}=100 \sim 500 & 54 \% \text { isolated yield }
\end{array}
$$

图式 19 铜催化 $\mathrm{CO}_{2}$ 氢化生成甲酸盐

Scheme 19 Cu-catalyzed hydrogenation of $\mathrm{CO} 2$ into formate

$\mathrm{Fe}-\mathrm{Mo}-\mathrm{V}_{2} \mathrm{O}_{5}$ 作为催化剂, $250 \sim 400{ }^{\circ} \mathrm{C}$ 下, 甲醇被过量 的空气氧化为甲醛, 收率可以达到 $99 \%$. 催化 $\mathrm{CO}_{2}$ 氢化 生成甲醛的难点在于过度还原为甲醇产物.

2013 年, Sabo-Etienn 课题组 ${ }^{[71]}$ 使用嗍烷作为氢源, 多氢 $\mathrm{Ru}$ 配合物 $\left[\mathrm{RuH}_{2}\left(\mathrm{H}_{2}\right)_{2}-\left(\mathrm{PCy}_{3}\right)_{2}\right](\mathrm{Cy}=$ 环己基)作为催 化剂催化 $\mathrm{CO}_{2}$ 氢化为甲醛的体系(Scheme 20). 机理研究 表明, 在温和条件下, 产物甲醛可伯胺原位缩合转化为 亚胺. 随后, 亚胺被水解生成了福尔马林溶液, 这是 $\mathrm{CO}_{2}$ 氢化生成甲醛的第一例.

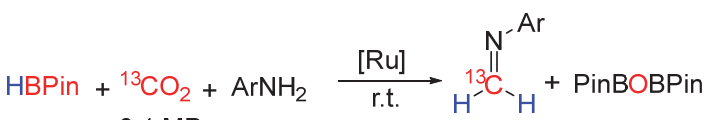

$$
\begin{aligned}
& 0.1 \mathrm{MPa} \\
& \mathrm{H}_{2} \mathrm{O} / \mathrm{CH}_{3} \mathrm{OH} \\
& \left({ }^{13} \mathrm{CH}_{2} \mathrm{O}\right)_{n}+\mathrm{ArNH}_{2}
\end{aligned}
$$

图式 20 多氢 $\mathrm{Ru}$ 配合物催化 $\mathrm{CO}_{2}$ 氢化还原为甲醛 Scheme 20 Hydrogenation of $\mathrm{CO}_{2}$ to formaldehyde catalyzed with polyhydride ruthenium complex

相比于嗍烷而言, 氢气是最理想的氢源. 丁奎岭课 题组 ${ }^{[72]}$ 报道了 $\mathrm{CO}_{2}$ 参与的 $\mathrm{Rh}$ 催化烯烃的氢甲酰化反应 (Scheme 21), 这个体系需要硅烷和氢气两种还原剂. 相 比于 $\mathrm{Ru}$ 或 $\mathrm{Rh}$ 催化 $\mathrm{CO}_{2}$ 参与的烯烃的氢鈴化、氢甲酯 化反应, 本体系具有条件温和 $\left[P\left(\mathrm{H}_{2} / \mathrm{CO}_{2}\right)=2.0 / 0.5 \mathrm{MPa}\right.$,

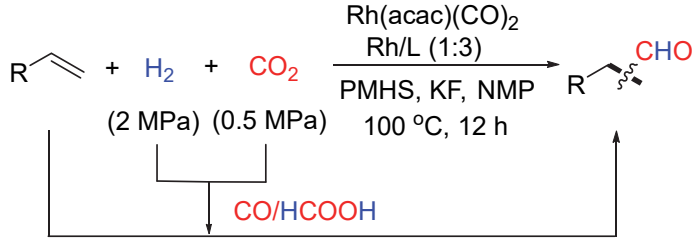

$[\mathrm{Rh}] / \mathrm{H}_{2}$

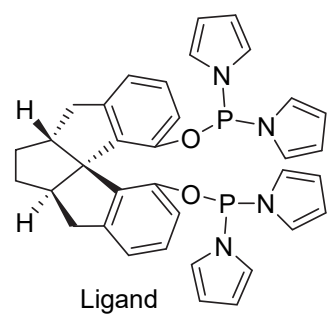

图式 $21 \mathrm{Rh}$ 催化 $\mathrm{CO}_{2}$ 参与的烯烃的氢甲酰化反应 Scheme 21 Rhodium-catalyzed hydroformylation of olefins with $\mathrm{CO}_{2}$ and hydrosilane

$100{ }^{\circ} \mathrm{C}, 12 \mathrm{~h}$ ]、产物收率和区域选择性高的优点. 机理 研究表明, 反应首先经历的是 $\mathrm{CO}_{2}$ 在硅烷作用下还原为 $\mathrm{CO}$ ，随后在 $\mathrm{Rh}$ 催化烯烃的 $\mathrm{H}_{2} / \mathrm{CO}$ 氢甲酰化反应，体系 生成的 $\mathrm{HCOOH}$ 有利于 $\mathrm{Rh}-\mathrm{H}$ 物种的生成进而促进反应.

最近, 孙予罕课题组 ${ }^{[73]}$ 报道了 $\mathrm{CO}_{2}$ 参与的 $\mathrm{Rh}$ 催化 烯烃的氢甲酰化反应合成烷基醛类化合物(Scheme 22), 使用 1,3,5-三氮杂-7-磷杂金刚烷(PTA)配体可以获得优 异的直链醛基化选择性. 大部分脂肪烯烃底物可以得到 较高的收率(64\% 97\%)，以直链型醛基化产物为主. 但是对于芳基烯烃而言，倾向于生成支链醛基化产物， 可能是因为在形成 $(\mathrm{PTA})_{3}(\mathrm{CO}) \mathrm{Rh}-\mathrm{H}$ 活性中间体时，芳 环与金属 $\mathrm{Rh}$ 中心有配位作用，反应位点在苄位. 控制 实验证明 $\mathrm{CO}_{2}-\mathrm{HCOOH}-\mathrm{HCOOAc}-\mathrm{CO}$-醛基产物的可能 性，并提出了经过 $\mathrm{CO}$ 或者经过 $\mathrm{HCOOAc}$ 中间体的两种 机理. 


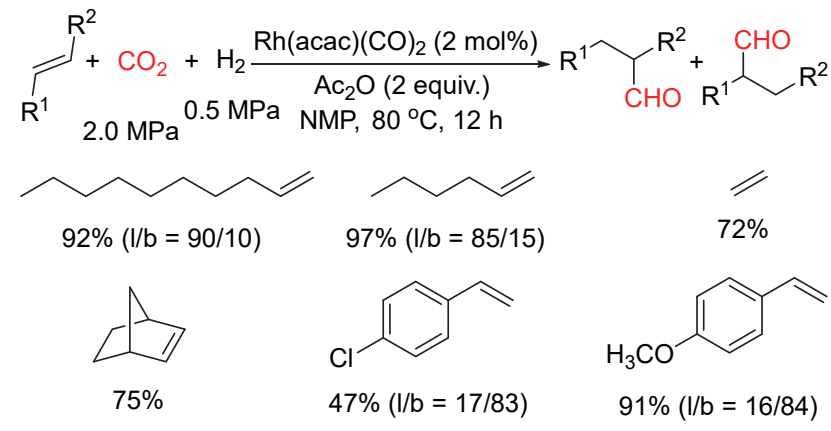

图式 $22 \mathrm{Rh}$ 催化烯烃的氢甲酰化反应

Scheme 22 Rh-catalyzed hydroformylation of alkenes with $\mathrm{CO}_{2} / \mathrm{H}_{2}$

\section{3 六电子氢化产物}

2020 年我国甲醇的年使用量超过了 7790 万吨, 是 化工行业最为重要的大宗化学品之一. 甲醇的用途广 泛, 主要用于生产甲醛(36\%)、甲基叔丁基醚和甲基叔戊 基醚 $(13 \%)$ 、乙酸 $(9 \%)$ 、乙二醇二甲醚(DME)、烯烃、 二甲醚、烯烃、甲胺、甲基丙烯酸酯、氯甲烷等 ${ }^{[74]}$ (图 5). 甲醇可催化裂解和重整为不同比例的 $\mathrm{CO} 、 \mathrm{H}_{2}$ 和 $\mathrm{CO}_{2}$ 的混合气体, 甲醇的潜在利用方式是将其视为 $\mathrm{H}_{2}$ 和 $\mathrm{CO}$ 的载体. 因此, 甲醇被视为等当量合成气的液态形式, 具有广泛的工业应用。商业化的甲醇合成催化剂 $\left(\mathrm{Cu}-\mathrm{ZnO}-\mathrm{Al}_{2} \mathrm{O}_{3}\right)$ 是通过共沉淀法进行合成, $\mathrm{CO}_{2}$ 氢化合 成甲醇的温度在 $200{ }^{\circ} \mathrm{C}$ 以上, 催化性能达到 $Y_{\mathrm{CH}_{3} \mathrm{OH}}=$ $15.2 \mathrm{~g}_{\mathrm{CH}_{3} \mathrm{OH}} \mathrm{g}_{\mathrm{cat}}{ }^{-1} \cdot \mathrm{h}^{-1}\left[{ }^{[7,75]}\right.$. 相比于非均相催化体系而言, 均相催化 $\mathrm{CO}_{2}$ 氢化合成甲醇的报道不多.

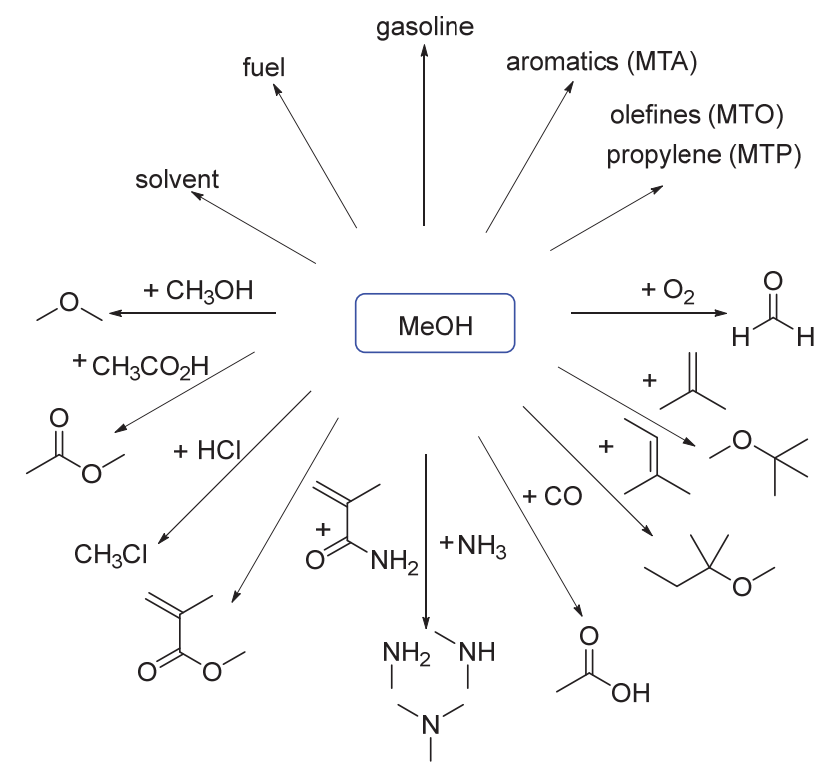

图 5 甲醇作为化学和能量载体的广泛用途

Figure 5 Methanol as a versatile platform chemical and energy carrier
我们将近来过渡金属催化 $\mathrm{CO}_{2}$ 、甲酸酯、嫝、碳酸 酯氢化生成甲醇的代表性工作列入表 4. 相比于非均相 催化体系, 有关均相催化 $\mathrm{CO}_{2}$ 氢化还原为甲醇的报道较 少. 主要由于在两电子还原的基础上进一步还原为甲醇 时需要更高的反应温度, 而均相金属配合物在高温下容 易降解失活，从而使其还原难度较大 ${ }^{[76]}$. 同时, $\mathrm{CO}_{2}$ 的 六电子还原至甲醇在动力学角度是不利的. 1993 年, Sasaki 和 Tominaga 等 ${ }^{[77]}$ 报道了 $\mathrm{Ru}_{3}(\mathrm{CO})_{12} / \mathrm{KI}$ 均相催化 体系氢化 $\mathrm{CO}_{2}$ 为甲醇、 $\mathrm{CO}$ 和甲烷. 在温度为 $240{ }^{\circ} \mathrm{C}$, $\mathrm{CO}_{2}$ 和 $\mathrm{H}_{2}$ 压力比为 $1: 3$, 总压为 $9 \sim 14 \mathrm{MPa}$, 甲醇的转 化数可达 32. 此外, 体系中的 $\mathrm{KI}$ 能够抑制 $\mathrm{Ru}$ 配合物的 分解, 起到稳定催化剂的作用, 从而提高甲醇的收率和 选择性，极大地抑制甲烷和乙烷的生成. 由于体系压力 较低，因此没有乙二醇生成. 更有趣的是，当使用双金 属催化体系 $\left.\left[\mathrm{Ru}_{3}(\mathrm{CO})_{12}\right] / \mathrm{Co}_{2}(\mathrm{CO})_{8}\right] / \mathrm{KI}$ 时，体系中通过甲 醇的二聚生成大量的乙醇. 在 $200{ }^{\circ} \mathrm{C}$ 下, $\mathrm{CO}_{2}$ 转化为 $\mathrm{CO}$ $(T O N=8)$ 、甲醇 $(T O N=31) 、 乙$ 醇 $(T O N=12)$ 、甲酸甲 酯 $(\mathrm{TON}=1)$ 和甲烷 $(\mathrm{TON}=13)$.

2011 年, Milstein 等 ${ }^{[78]}$ 报道了 $\mathrm{Ru} / \mathrm{PNN}$ 三齿配体用 于催化 $\mathrm{CO}_{2}$ 氢化生成的中间体, 其中包括甲酸酯、碳酸 二甲酯、氨基甲酸酯、艮的衍生物以及甲酰胺等，甲醇 是主要氢化产物(图 6). 当使用 $\mathrm{Ru} /$ Pincer 催化剂用于碳 酸二甲酯的氢化时, 其可定量的还原为甲醇, TOF 可达 $2500 \mathrm{~h}^{-1}\left(6 \mathrm{MPa} \mathrm{H}, 145{ }^{\circ} \mathrm{C}\right)$. 同时, 由 $\mathrm{CO}_{2}$ 衍生的甲酸 甲酯同样可被氢化为甲醇, $T O F=531 \mathrm{~h}^{-1}(5 \mathrm{MPa} \mathrm{H}$, $\left.110{ }^{\circ} \mathrm{C}\right)$. 在大多烷基以及芳基嫝衍生物中，1,3-二己基 脲以较高的收率(46\% 94\%)还原为甲醇( $1.36 \mathrm{MPa} \mathrm{H}_{2}$, $\left.110{ }^{\circ} \mathrm{C}\right)$; 甲酰吗啉也在相似的反应条件下以 $97 \%$ 的收 率转化为甲醇.

同年, Sanford 课题组 ${ }^{[79]}$ 通过串联反应的策略, 在同 一反应体系中使用三种不同的均相催化剂 $\left(\mathrm{PMe}_{3}\right)_{4}-$ $\mathrm{Ru}(\mathrm{Cl})(\mathrm{OAc}) 、 \mathrm{Sc}(\mathrm{OTf})_{3}$ 和( $\left.\mathrm{PNN}\right) \mathrm{Ru}(\mathrm{CO})(\mathrm{H})$, 可实现 $\mathrm{CO}_{2}$ 氢化为甲醇 (Scheme 23). 这三种催化剂的作用分别是: (1)催化 $\mathrm{CO}_{2}$ 氢化生成甲酸, (2)促进甲酸与醇发生酯化反 应，(3)甲酸酯氢化为甲醇产物. 通过类似的策略, 以 $\mathrm{Ru}-\mathrm{MACHO}-\mathrm{BH}_{4}$ 作为催化剂实现了 $\mathrm{CO}_{2}$ 直接氢化还原 生成甲醇. 反应的历程分为三步: (1)催化 $\mathrm{CO}_{2}$ 氢化生成 甲酸, (2)甲酸与二甲胺缩合生成 DMF, (3) DMF 氢化为 甲醇产物 ${ }^{[80]} .2012$ 年, Klankermayer 和 Leitner 课题组 ${ }^{[81]}$ 报道了使用单一金属配合物 $[\mathrm{Ru}(\operatorname{triphos})(\mathrm{tmm})] / \mathrm{H}^{+}$催化 体系实现了 $\mathrm{CO}_{2}$ 的串联氢化生成甲醇. 该催化体系在相 对温和的反应条件下 $\left(P_{\mathrm{CO}_{2}}=2 \mathrm{MPa}, P_{\mathrm{H}_{2}}=6 \mathrm{MPa}\right.$, $\left.140{ }^{\circ} \mathrm{C}\right)$, 直接氢化 $\mathrm{CO}_{2}$ 为甲醇, 最高 $\mathrm{TON}=63$. 
表 $4 \mathrm{CO}_{2} /$ 甲酸酯/腿/碳酸酯的催化氢化合成甲醇

Table 4 Hydrogenation of $\mathrm{CO}_{2} /$ formate/urea/carbonate for the synthesis of methanol

\begin{tabular}{|c|c|c|c|c|c|c|c|c|c|}
\hline Catalyst precursor & Substrate & Solvent & Additive & $P\left(\mathrm{CO}_{2} / \mathrm{H}_{2}\right)$ & ${ }^{a} T /{ }^{\circ} \mathrm{C}$ & Time $/ h^{-1}$ & TON & $\mathrm{TOF} / \mathrm{h}^{-1}$ & Ref. \\
\hline$\left[\mathrm{Ru}_{3}(\mathrm{CO})_{12}\right]$ & $\mathrm{CO}_{2}$ & NMP & KI & $2 / 6$ & 240 & 3 & 32 & 10 & [77] \\
\hline $\begin{array}{l}{[\mathrm{Ru}(\mathrm{Cl})(\mathrm{OAc})(\mathrm{PMe})] / \mathrm{Sc}(\mathrm{OTf}) /} \\
{[(\mathrm{PNN}) \mathrm{Ru}(\mathrm{H})(\mathrm{CO})]}\end{array}$ & $\mathrm{CO}_{2}$ & 1,4-Dioxane & - & $1 / 3$ & 75 & 16 & 21 & 1.3 & [79] \\
\hline$[(\mathrm{PNP}) \mathrm{Ru}(\mathrm{HBH}) \mathrm{H}(\mathrm{CO})]$ & $\mathrm{CO}_{2}$ & THF & $\mathrm{K}_{3} \mathrm{PO}_{4}$ & $0.25 / 5$ & 95 & 54 & 550 & 10 & [80] \\
\hline$[\mathrm{Ru}(\text { triphos })(\mathrm{tmm})]_{2}$ & $\mathrm{CO}_{2}$ & THF & $\mathrm{EtOH}$ & $2 / 6$ & 140 & 24 & 221 & 37 & [81] \\
\hline$[(\mathrm{PNN}) \mathrm{Ru}(\mathrm{H}) \mathrm{Cl}(\mathrm{CO})]$ & $\mathrm{CO}_{2}$ & DMSO & $\mathrm{Cs}_{2} \mathrm{CO}_{3} / \mathrm{K}_{3} \mathrm{PC}$ & $40.1 / 6$ & 150 & 96 & $\mathrm{n} / \mathrm{a}^{b}$ & $\mathrm{n} / \mathrm{a}$ & [82] \\
\hline$\left[(\mathrm{PNP}) \mathrm{Ru}\left(\mathrm{HBH}_{3}\right) \mathrm{H}(\mathrm{CO})\right]$ & $\mathrm{CO}_{2}$ & THF & $\mathrm{PEHA}^{c}, \mathrm{~K}_{3} \mathrm{PC}$ & $0.75 / 6.75$ & 145 & 200 & 1200 & 6 & {$[100]$} \\
\hline$[(\mathrm{PNP}) \mathrm{Ru}(\mathrm{H}) \mathrm{Cl}(\mathrm{CO})]$ & Ethylene carbonate & THF & $\mathrm{KOtBu}$ & $0 / 6$ & 140 & 72 & 87000 & 1200 & {$[104]$} \\
\hline$[(\mathrm{PNN}) \mathrm{Ru}(\mathrm{H})(\mathrm{CO})]$ & urea & THF & - & $0 / 1.36$ & 110 & 72 & $\mathrm{n} / \mathrm{a}$ & $\mathrm{n} / \mathrm{a}$ & [78] \\
\hline$[(\mathrm{PNN}) \mathrm{Ru}(\mathrm{H})(\mathrm{CO})]$ & HCOOMe & THF & - & $0 / 5$ & 110 & 14 & 4700 & 335 & {$[106]$} \\
\hline$\left[\mathrm{FeCl}_{2}\left\{\kappa^{3}-\mathrm{HC}(\mathrm{pz})_{3}\right\}\right]$ & $\mathrm{CO}_{2}$ & - & PEHA & $1.9 / 5.6$ & 80 & 36 & 2387 & 66 & [87] \\
\hline$[(\mathrm{PNP}) \mathrm{Fe}(\mathrm{H})(\mathrm{CO})]$ & $\mathrm{CO}_{2}$ & 1,4-Dioxane & Morpholine & $1.7 / 7.9$ & 100 & 16 & 590 & 37 & [88] \\
\hline$\left[(\mathrm{PNP}) \mathrm{MnBr}(\mathrm{CO})_{2}\right]$ & $\mathrm{CO}_{2}$ & THF & $\mathrm{K}_{3} \mathrm{PO}_{4}$ & $3 / 3$ & 110 & $24 \sim 36$ & 36 & $\mathrm{n} / \mathrm{a}$ & {$[107]$} \\
\hline $\mathrm{Co}\left(\mathrm{BF}_{4}\right)_{2} \bullet 6 \mathrm{H}_{2} \mathrm{O} / \mathrm{PP}_{3}$ & $\mathrm{CO}_{2}$ & THF/EtOH & $\mathrm{HNTf}_{2}$ & $2 / 7$ & 100 & 24 & 50 & 2 & {$[108]$} \\
\hline
\end{tabular}

${ }^{a} \mathrm{MPa} ;{ }^{b} \mathrm{n} / \mathrm{a}=$ not available; ${ }^{c}$ pentaethylenehexamine.

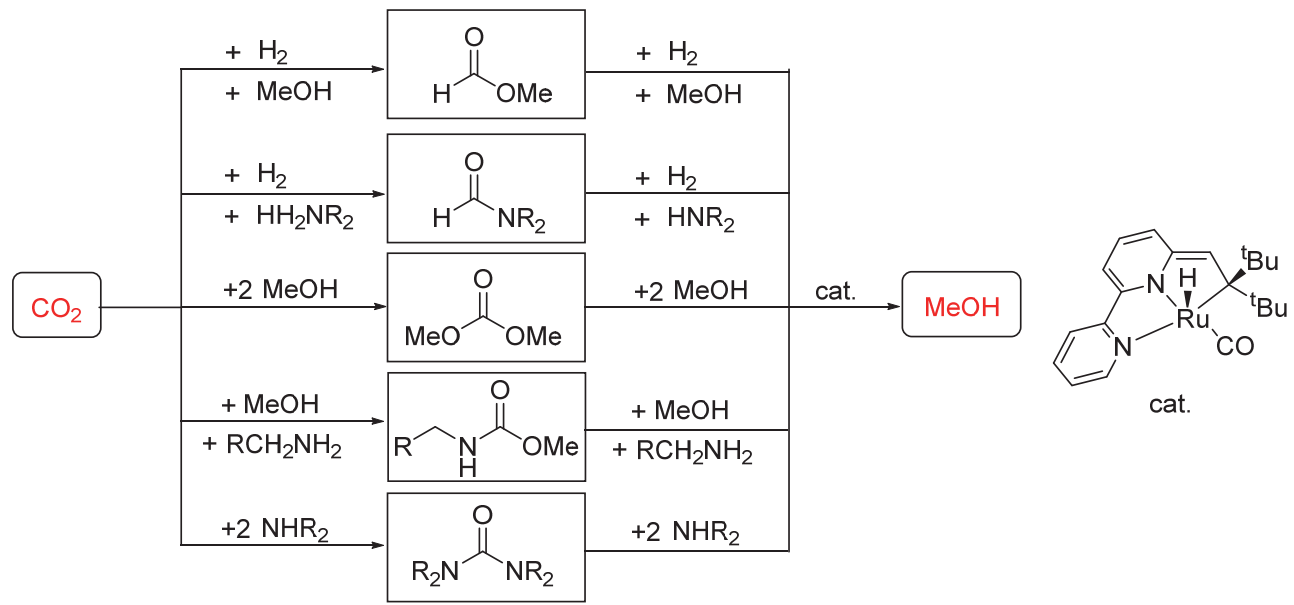

图 6 甲醇的间接合成

Figure 6 Indirect routes to methanol from $\mathrm{CO}_{2}$

上述的报道使用的是单金属催化剂，产物为甲醇. 后续的报道大多使用的是 $\mathrm{Ru} / \mathrm{Rh}$ 双金属催化剂，可生成 结构更为多样化的八电子还原产物. 2015 年, 韩布兴课 题组 ${ }^{[83}$ 报道了 $\left[\mathrm{Ru}_{3}(\mathrm{CO})_{12}\right] /\left[\mathrm{Rh}_{2}(\mathrm{CO})_{4} \mathrm{Cl}_{2}\right]$ 双金属催化体 系氢化 $\mathrm{CO}_{2}$ 生成 $\mathrm{C}_{2}$ 醇, 在以 $\mathrm{LiI}$ 为促进剂, 以 $\mathrm{DMI}$ 为 溶剂的条件下具有高达 $96.4 \%$ 的选择性. 此外, $160{ }^{\circ} \mathrm{C}$ 是报道至今利用 $\mathrm{CO}_{2}$ 合成 $\mathrm{C}_{2}$ 醇的最低温度(Scheme 24).

此外, $\mathrm{Ru}-\mathrm{Al}$ 双金属协同催化 ${ }^{[84]} \mathrm{CO}_{2}$ 氢化合成二烷 氧基甲烷的反应经历了两次氢化(Scheme 25): (1) $\mathrm{CO}_{2}$ 先被还原生成甲酸，随后与体系中的甲醇发生酯化反应 生成甲酸酯; (2)甲酸酯进一步还原生成了半缩醛, 然后 再与一分子甲醇生成 DMM 产物. 在整个氢化还原过程 中, $\mathrm{CO}_{2}$ 本质上被还原为醇类化合物.

2020 年, 孙文华等 ${ }^{[85}$ ]报道了使用一种新型的双膦
$\mathrm{Ru}\left(\mathrm{II}\right.$ )催化剂实现了 $\mathrm{CO}_{2}$ 的氢化还原为甲醇(图 7), 随后 原位与体系中的羧酸缩合生成羧酸酯, 最高 TON 为 3260 , 芳香族和脂肪族羧酸均可有效地转化为相应的甲 酯产物. 此方法利用 $\mathrm{CO}_{2}$ 氢化策略为精细化学品和甲醇 的合成提供了新思路.

同年，Klankermayer 课题组 ${ }^{[86]}$ 报道了三齿膦配体螯 合的 $\mathrm{Ru}$ 催化剂对 $\mathrm{CO}_{2}$ 的六电子还原为甲醇. 与 $\mathrm{CO}_{2}$ 氢 化合成甲醇的大部分例子不同之处在于，该催化循环不 需要经历甲酰胺或者甲酸酯中间体直接将 $\mathrm{CO}_{2}$ 还原为 甲醇(图 8). 在四氢呋喃溶液中, 这种 $\mathrm{Ru}$ 配合物表现出 很高的催化活性, TON 达 1100; 在乙醇溶剂中, 催化效 率更高, TON 高达 2100. 此外, 该催化反应在非极性的 长链醇(正辛醇、正癸醇) $/ \mathrm{H}_{2} \mathrm{O}$ 两相体系中很好地进行, 甲醇产物可以溶于水中并且易分离. 

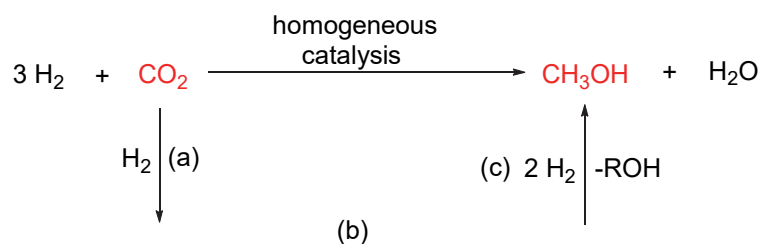

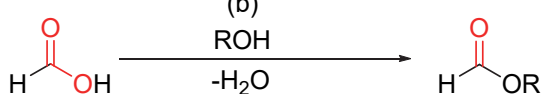

a:

b:

C:

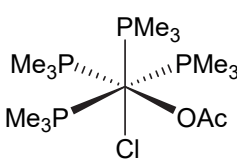

$\mathrm{Sc}(\mathrm{OTf})_{3}$

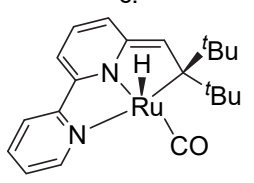

$\mathrm{CO}_{2}+\mathrm{HNMe}_{2} \stackrel{-\mathrm{H}_{2} \mathrm{O}}{\longrightarrow} \mathrm{HCONMe}_{2} \frac{+2 \mathrm{H}_{2}}{-\mathrm{HNMe}_{2}} \mathrm{CH}_{3} \mathrm{OH}$

图式 23 串联反应策略用于 $\mathrm{CO}_{2}$ 氢化合成甲醇

Scheme 23 Cascade reactions for the hydrogenation of $\mathrm{CO}_{2}$ to methanol

$$
\begin{aligned}
& {\left[\mathrm{Ru}_{3}(\mathrm{CO})_{12}\right] /\left[\mathrm{Rh}_{2}(\mathrm{CO})_{4} \mathrm{Cl}_{2}\right]} \\
& \mathrm{CO}_{2}+\mathrm{H}_{2} \underset{\text { 1,3-dimethyl-2-imidazolidinone }}{\longrightarrow} \mathrm{R} \\
& \geq 160{ }^{\circ} \mathrm{C}, 12 \mathrm{~h} \quad \mathrm{R}: \mathrm{Me}-, \text { Et-, }{ }^{n} \mathrm{Pr}-,{ }^{\prime} \mathrm{Pr}-, \text { 'butyl- } \\
& \mathrm{CO}_{2} / \mathrm{H}_{2}(4 / 4 \mathrm{MPa}) \quad \mathrm{C}_{2+} \text { alcohols with } 96.4 \% \text { selectivity }
\end{aligned}
$$

图式 24 双金属 $\mathrm{Ru} / \mathrm{Rh}$ 体系催化 $\mathrm{CO}_{2}$ 氢化生成 $\mathrm{C}_{2}$ 醇 Scheme 24 Synthesis of $\mathrm{C}_{2}$ alcohols by $\mathrm{CO}_{2}$ hydrogenation with a homogeneous bimetallic $\mathrm{Ru} / \mathrm{Rh}$ system

关于丰产金属催化 $\mathrm{CO}_{2}$ 氢化合成甲醇, $\left[\mathrm{FeCl}_{2}\left\{\kappa^{3}-\right.\right.$ $\left.\left.\mathrm{HC}(\mathrm{pz})_{3}\right\}\right] \quad\left(\mathrm{pz}=\right.$ pyrazol-1-yl)配合物 ${ }^{[87]}$ 可在五乙烯六胺 存在下直接催化 $\mathrm{CO}_{2}$ 氢化合成甲醇, 收率为 $44 \%, \mathrm{TON}$ 高达 2387(图 9). 随后, 研究发现, [(PNP)Fe(H)(CO)] 配 合物催化 $\mathrm{CO}_{2}$ 氢化制甲醇 ${ }^{[88]}$, 反应分步进行: (1)在胺作 用下, $\mathrm{CO}_{2}$ 被氢气还原为甲酰胺; (2)随后, 甲酰胺进一步 还原为甲醇和胺, 最高 $\mathrm{TON}$ 为 $590 . \mathrm{Co}$ 和 $\mathrm{Mn}$ 的配合物 也可催化 $\mathrm{CO}_{2}$ 氢化合成甲醇, 但效率较低 ${ }^{[107-108]}$.

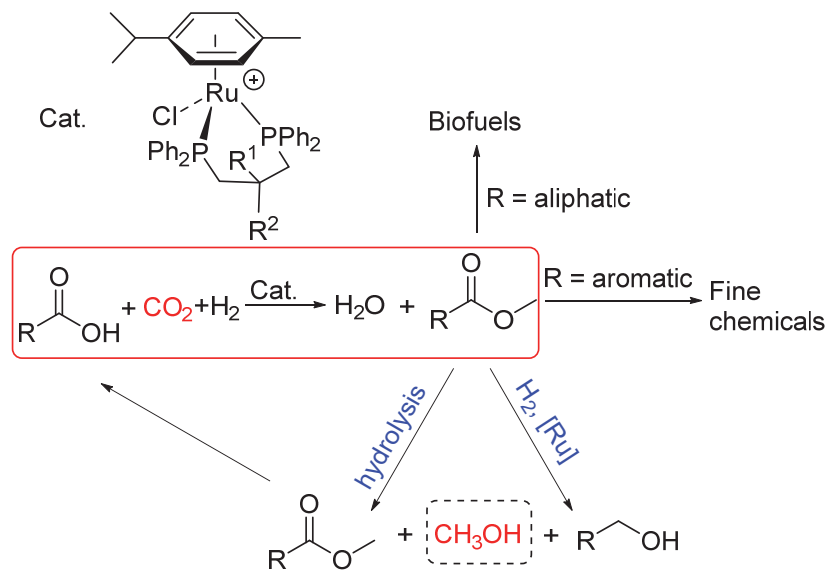

图 7 串联反应应用于 $\mathrm{CO}_{2}$ 氢化合成羧酸甲酯 Figure 7 Cascade reactions for the hydrogenation of $\mathrm{CO}_{2}$ to carboxylate ester

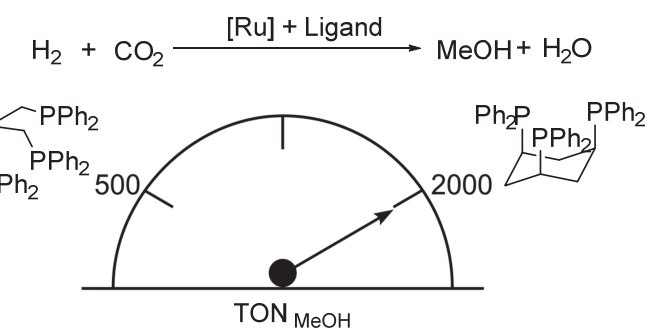

图 $8 \mathrm{Ru} / \mathrm{P}_{3}$ 配合物催化 $\mathrm{CO}_{2}$ 氢化合成甲醇

Figure $8 \mathrm{Ru} / \mathrm{P}_{3}$-catalyzed hydrogenation of $\mathrm{CO}_{2}$ to methanol

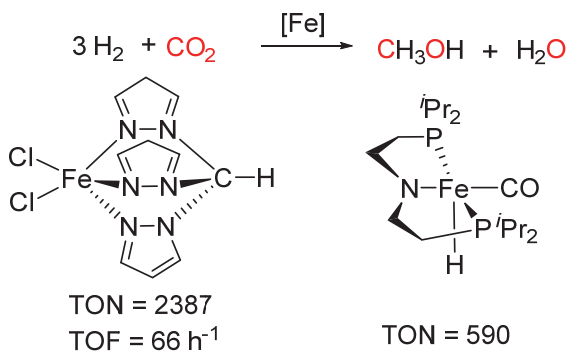

图 $9 \mathrm{Fe}$ 催化 $\mathrm{CO}_{2}$ 氢化合成甲醇

Figure 9 Fe-catalyzed hydrogenation of $\mathrm{CO}_{2}$ to methanol

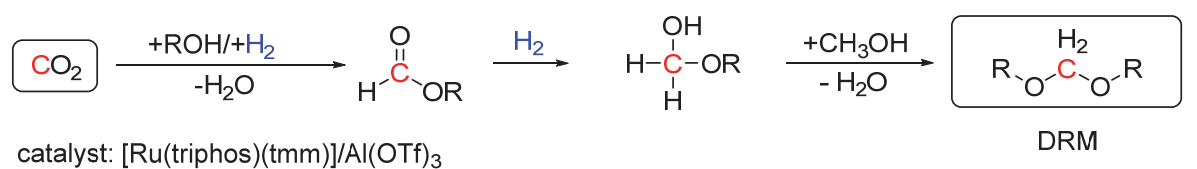
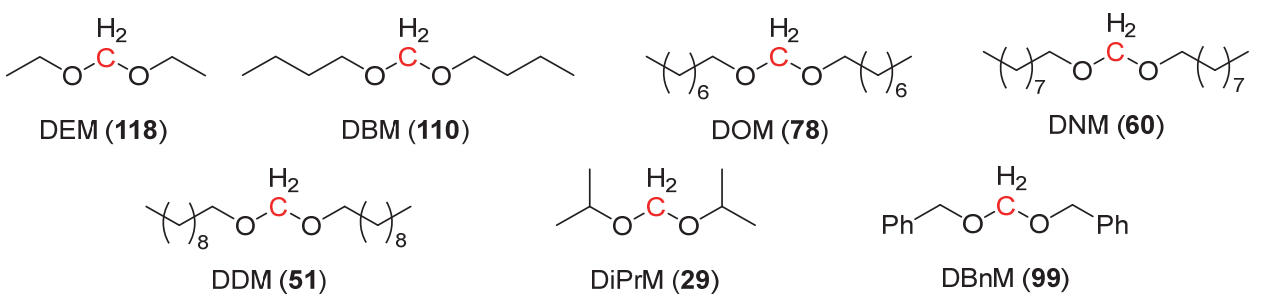

图式 $25 \mathrm{Ru}$ 催化 $\mathrm{CO}_{2}$ 氢化合成 DRM

Scheme 25 Ruthenium-catalyzed synthesis of dialkoxymethanes 
近年来发展的 $6 \mathrm{e}$ 还原还包括 $\mathrm{CO}_{2}$ 参与不饱和烃的 不对称还原羟甲基化反应, 所使用的底物包括芳基乙烯

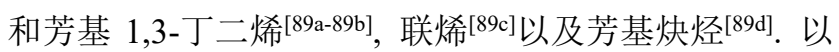
硅烷作为还原剂, 铜催化产生的 $\mathrm{Cu}-\mathrm{H}$ 物种与不饱和 烃, 形成 $\mathrm{C}-\mathrm{Cu}$ 键的中间体; 随后 $\mathrm{CO}_{2}$ 插入 $\mathrm{C}-\mathrm{Cu}$ 键 生成的羧酸, 进一步被硅烷还原为羟甲基化产物.

\section{$4 \mathrm{CO}_{2}$ 的原位催化氢化}

CCS (Carbon capture and sequestration)策略是规模 化减缓 $\mathrm{CO}_{2}$ 排放的手段之一, 但其脱附、压缩、运输和 储存过程中, 不可避免地消耗能量 ${ }^{[00]}$. 着眼于 $\mathrm{CO}_{2}$ 吸收 和资源化利用相结合的策略(CCU, Carbon Capture and Utilization), 将 $\mathrm{CO}_{2}$ 的吸收产物进行原位氢化, 既可绕 过脱附、压缩环节, 减少设备投入及节能降耗 ${ }^{[91]}$; 同时, 吸收过程中 $\mathrm{CO}_{2}$ 分子得到活化, 有利于后续化学转化在 低压温和条件下进行. 现有的吸收体系脱附 $\mathrm{CO}_{2}$ 能耗 高, 吸收量和吸收速率还有待提高, 这成为影响 CCS 在 工业上应用的重要因素. 因此, 改进吸收剂和吸收方法 以减少能量投入是当今 CCS 技术的关键. 更为重要的 是, 吸收剂通过化学反应对气态 $\mathrm{CO}_{2}$ 的吸收可以得到盐 类化合物, 同时碳氧中心被活化, 因此可以认为, 化学 吸收的过程是在常压下对 $\mathrm{CO}_{2}$ 活化的过程. 如果能够将 $\mathrm{CO}_{2}$ 的吸收和资源化利用相结合, 即利用吸收的 $\mathrm{CO}_{2}$ 作 为反应的起始原料, 绕过脱附、压缩等耗能过程. 因此,
$\mathrm{CO}_{2}$ 经过吸收和预活化后能够直接转化为高附加值的化 学品 ${ }^{[92]}$. 鉴于 $\mathrm{CO}_{2}$ 吸收和资源化利用相结合的策略，设 想将 $\mathrm{CO}_{2}$ 的催化氢化反应作为重要的资源化利用的途 径引入到 $\mathrm{CCU}$ 中来, 能在节能的同时获得更多的化石 燃料能源替代物，将具有重大的意义，该方法为 $\mathrm{C}_{1}$ 资源 的转化提供了新思路. 在这里将我们主要介绍 $\mathrm{CO}_{2}$ 的捕 集及其后续催化氢化反应相结合的策略，以及应用于甲 酸和甲醇的制备, 重点分析讨论了 $\mathrm{CO}_{2}$ 的原位催化氢化 反应机理和最新进展.

\section{1 有机胺捕集 $\mathrm{CO}_{2}$ 氢化还原为甲酸盐}

\subsection{1 非水溶液或者无溶剂体系}

尽管在过去十年，有许多报道涉及到使用均相和非 均相催化 $\mathrm{CO}_{2}$ 氢化生成甲酸盐 ${ }^{[93]}$, 但是关于 $\mathrm{CO}_{2}$ 的捕集 与原位氢化转化的报道却相对较晚. 我们课题组发展了 聚乙二醇/超强碱、离子液体、氨基碱体系用于捕集，活 化以及原位转化 $\mathrm{CO}_{2}$ 生成高附加值化学品, 包括碳酸 酯、艮、噁唑啉酮、甲酸和甲酸盐等 ${ }^{[92 a-92 c]}$, 在 $\mathrm{CO}_{2}$ 的 捕集利用方面做了系列开创性的工作(表 5, 图 10).

2013 年, 我们使用聚乙烯亚胺在甲醇溶液中捕集 $\mathrm{CO}_{2}$, 随后在 $\mathrm{Rh}$ 催化剂的作用下, 将捕集 $\mathrm{CO}_{2}$ 生成的中 间体原位氢化为甲酸盐(表 5, Entry 1; Scheme 26) ${ }^{[94]}$. 在 该体系中, 活性催化剂是 $\mathrm{Rh}$ 的金属前驱体与膦配体原 位形成的. 在乙二醇溶液中，当使用 1,5 -二氮杂双环

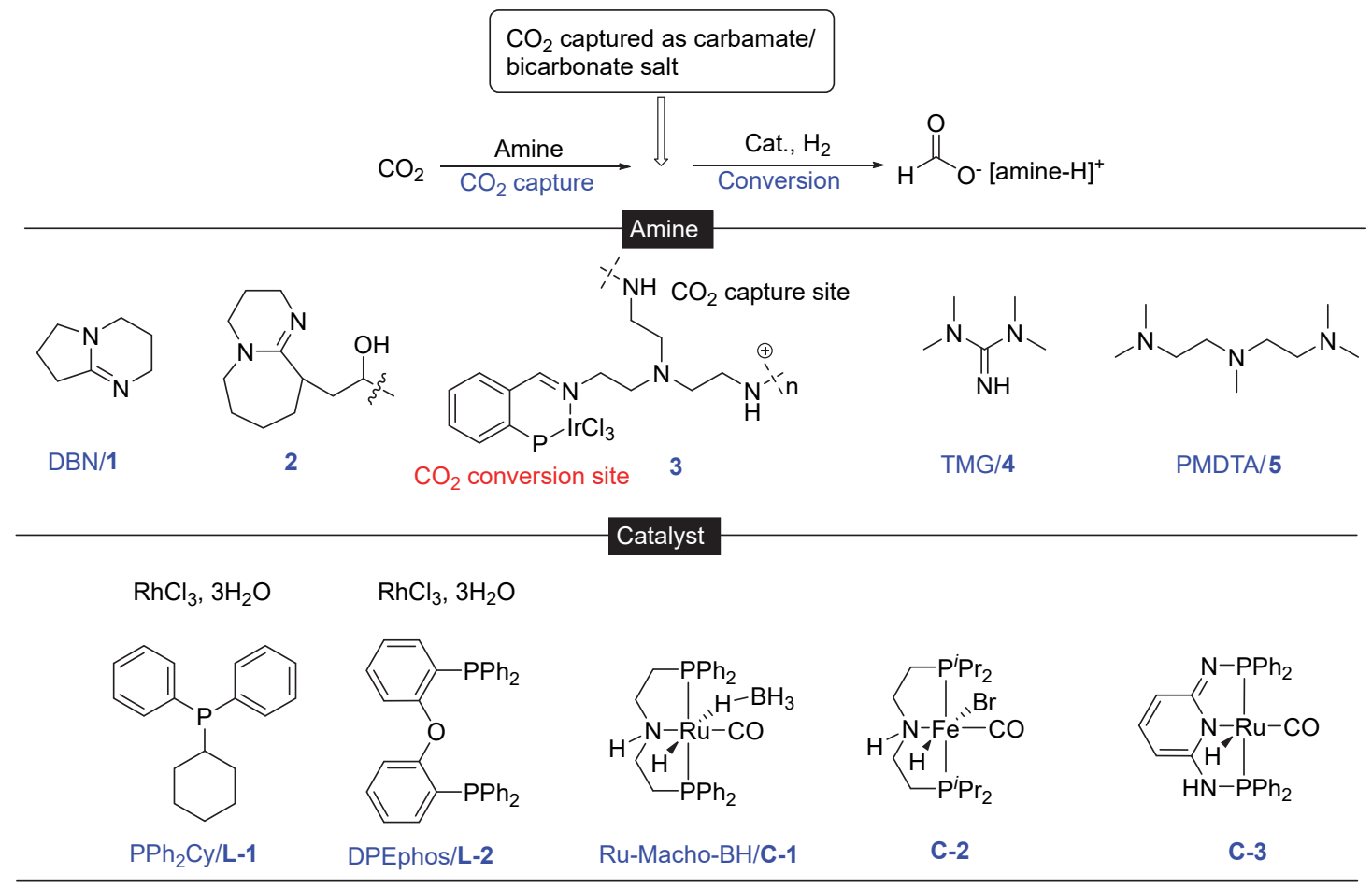

图 10 二氧化碳的捕集与原位氢化为甲酸盐举例

Figure 10 Selected examples of integrated $\mathrm{CO}_{2}$ capture with amine and conversion to formate 
表 5 二氧化碳的捕集与原位氢化为甲酸盐举例

Table 5 Selected examples of integrated $\mathrm{CO}_{2}$ capture with amine and conversion to formate

\begin{tabular}{clccclccc}
\hline Entry & Amine & Capture solvent & Captured as $^{a}$ & Precat. & $P\left(\mathrm{H}_{2}\right) / \mathrm{MPa}$ & $T /{ }^{\circ} \mathrm{C}(t / \mathrm{h})$ & Yield/\% $(\mathrm{TON})$ & $\mathrm{Ref}$. \\
\hline 1 & 1 & Glycol & $\mathrm{b}$ & $\mathrm{RhCl}_{3} \cdot 3 \mathrm{H}_{2} \mathrm{O}+\mathbf{L}-\mathbf{1}^{b}$ & 4.0 & $60(16)$ & $55(726)$ & {$[86]$} \\
2 & 2 & - & $\mathrm{b}$ & $\mathrm{RhCl}_{3} \cdot 3 \mathrm{H}_{2} \mathrm{O}+\mathbf{L}-\mathbf{2}^{b}$ & 4.0 & $60(16)$ & $97(169)$ & {$[87]$} \\
3 & 3 & - & $c$ & $d$ & 2.0 & $120(1)$ & $\mathrm{n}^{\mathrm{a}} \mathrm{a}^{g}(248)$ & {$[89]$} \\
4 & 4 & Water & $\mathrm{b}$ & $\mathbf{C}-\mathbf{1}$ & 5.0 & $55(20)$ & $95(7375)$ & {$[90]$} \\
5 & PEHA $^{e}$ & Water & $\mathrm{b}+\mathrm{c}$ & $\mathbf{C}-2$ & 8.0 & $50(10)$ & $53(255)$ & {$[90]$} \\
6 & 5 & Water & $\mathrm{b}$ & $\mathbf{C - 3}$ & 11.0 & $130(12)$ & $93(700)$ & {$[90]$} \\
\hline
\end{tabular}

${ }^{a} \mathrm{CO}_{2}$ was captured as either bicarbonate (b) or carbamate (c). ${ }^{b}$ The catalyst was formed in situ. ${ }^{c}$ A separate capture step was not performed. ${ }^{d}$ The catalytic center was incorporated into the amine (3). ${ }^{e}$ Pentaethylenehexamine. ${ }^{f}$ The active catalyst species formed in situ. ${ }^{g} \mathrm{n} / \mathrm{a}=$ not available.

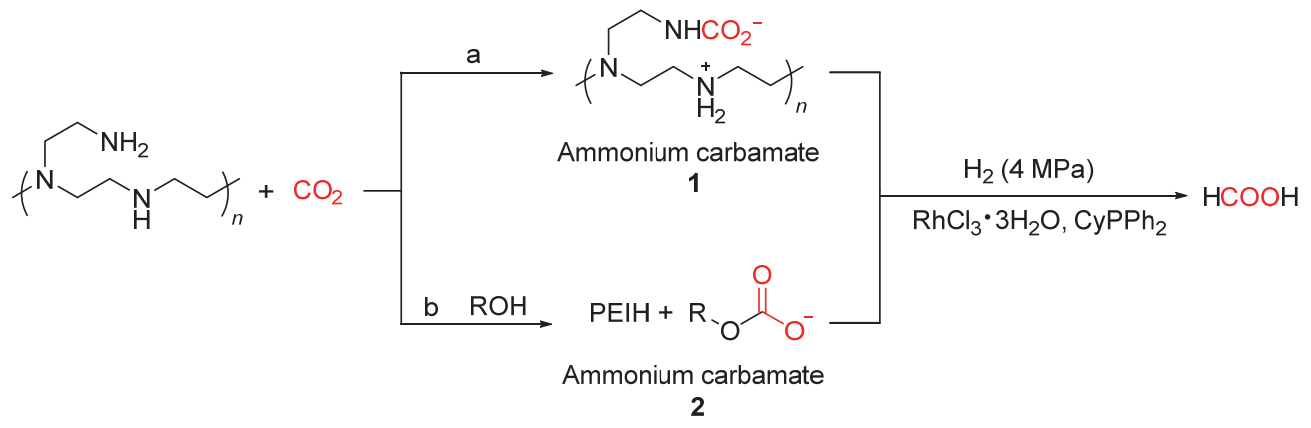

图式 26 聚乙烯亚胺用于 $\mathrm{CO}_{2}$ 的捕集与氢化合成甲酸

Scheme 26 Polyamine used for the $\mathrm{CO}_{2}$ capture and hydrogenation for the synthesis of formic acid

[4.3.0]壬-5-烯(DBN) 捕获 $\mathrm{CO}_{2}$ 时 (6 mmol DBN/7.2 $\mathrm{mmol}$ 乙二醇), 在 $\mathrm{RhCl}_{3} \cdot 3 \mathrm{H}_{2} \mathrm{O}$ 和 $\mathrm{PPh}_{2} \mathrm{Cy}$ 膦配体的作用 下获得了最好的催化活性，甲酸盐的产率为 $55 \%$, 最高 TON 可达 726. 在 $\mathrm{CO}_{2}$ 的捕获过程中, 乙二醇可以捕获 $\mathrm{CO}_{2}$ 形成的碳酸盐. 同时, 还需要注意的是, 当使用聚 乙烯亚胺 $\left(\mathrm{PEI}_{600}\right)$ 作为 $\mathrm{CO}_{2}$ 吸收剂时, $\mathrm{PEI}_{600}$ 中的氮原子 和金属 $\mathrm{Rh}$ 中心有相互作用, 因此聚多胺在催化体系中 可能还具有配体的作用，与金属 Rh 中心有较弱的配位.

使用苯并丁二酰亚胺钾盐作为 $\mathrm{CO}_{2}$ 吸收剂, 在室温 条件下几乎可以定量的吸收 $\mathrm{CO}_{2}$, 随后在 $\mathrm{RhCl}_{3} \cdot \mathrm{H}_{2} \mathrm{O}$ 的 催化作用下将捕集的 $\mathrm{CO}_{2}$ 原位氢化还原为甲酸, 可以获 得 $74 \%$ 的收率 ${ }^{[95]}$ (Scheme 27). 此外, 我们借鉴超强有机 碱功能化的质子型离子液体体系, 设计了以榺类衍生物 作为 $\mathrm{CO}_{2}$ 捕集剂的催化体系(表 5, Entry 2; Scheme 26) ${ }^{[96]}$. 结果表明, 比 $\mathrm{PPh}_{2} \mathrm{Cy}$ 更为优异的膦配体 DPEphos (L-2), 在相似的反应条件下, 最高 TON 可以 达到 516. 同年, McNamara 和 Hicks 等 ${ }^{[97]}$ 报道了可调控 的多功能 PEI 材料用于吸附 $\mathrm{CO}_{2}$, 随后在 Ir 催化剂的作 用下 $\mathrm{CO}_{2}$ 氢化合成甲酸(表 5, Entry 3). 所设计的复合型 PEI 催化剂中的两类结构片段可以协同完成氢化反应, 其作用分别如下, 即(1)通过 PEI 捕集 $\mathrm{CO}_{2}$, (2) 使用 Ir 配 合物催化 $\mathrm{CO}_{2}$ 的氢化, (3) PEI 催化剂可以稳定甲酸产物. 虽然该体系只能在 $2 \mathrm{MPa}$ 的 $\mathrm{CO}_{2}$ 氛围中完成捕集才能实 现后续的原位转化, 但是也可为多功能复合型催化体
系的设计提供借鉴.
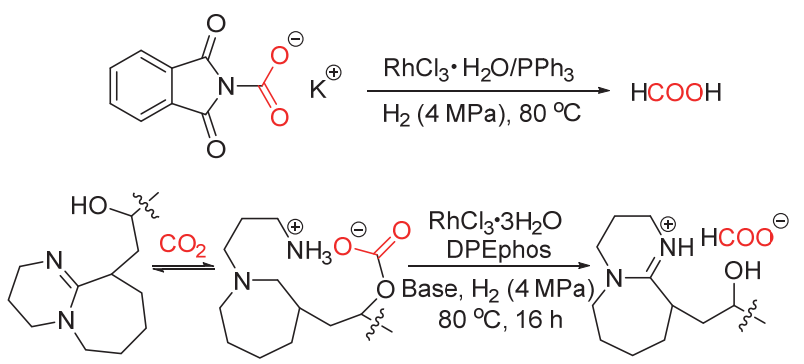

图式 27 邻苯二甲酰亚胺盐及咪类衍生物用于 $\mathrm{CO}_{2}$ 的捕集与 氢化

Scheme 27 Phthalimide salts and amidino alcohol derivative used in $\mathrm{CO}_{2}$ capture and hydrogenation

\subsection{2 有机胺的水溶液体系}

2016 年, Prakash 课题组 ${ }^{[98]}$ 报道了胺的水溶液用于 捕集 $\mathrm{CO}_{2}$ ，随后在 $\mathrm{Ru} / \mathrm{PNP}$ 配合物的催化作用下将捕集 的 $\mathrm{CO}_{2}$ 原位氢化为甲酸盐(表 5, Entries 4,5 ; 图 11). 本 研究的亮点在于: (1)使用有机胺的水溶液捕集 $\mathrm{CO}_{2}$, 容 易放大反应; (2)催化反应在两相溶液中进行，催化剂利 于回收; (3)除了 Ru配合物以外, Fe 配合物也可以用于该 体系并展现出很好的催化活性. 催化剂的可回收以及水 相反应的特性使得放大反应能够顺利进行。当使用 TMG (4)作为碱, Ru-Macho-BH (C-1)作为氢化催化剂 时，反应生成甲酸的收率为 $95 \%$, TON 高达 7375 , 所生 


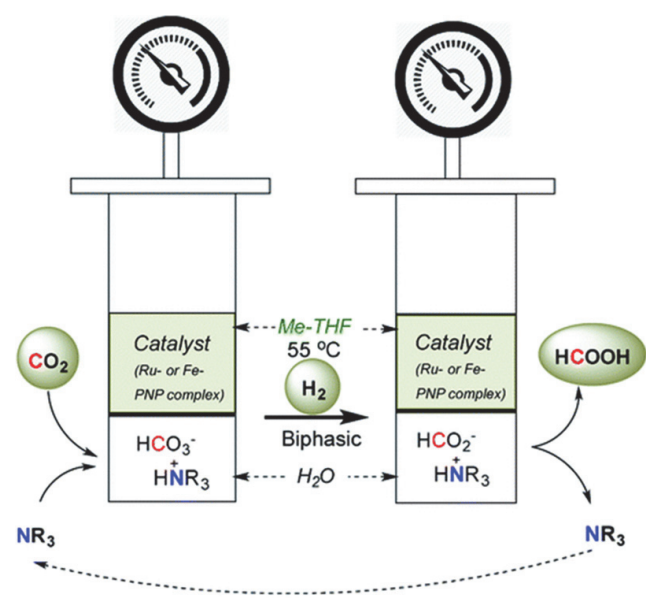

图 11 两相体系中催化剂的回收

Figure 11 Catalyst recycling in a biphasic reaction system

成的甲酸负离子从金属 $\mathrm{Ru}$ 中心的脱附是反应的决速步. 2018 年, Huang 课题组 ${ }^{[99]}$ 使用了类似的策略, 采用五甲 基二乙烯三胺(PMDTA) 作为 $\mathrm{CO}_{2}$ 捕获剂, 甚至可以捕获 空气中的 $\mathrm{CO}_{2}$, 最终使用氮膦三齿配体螯合的 $\mathrm{Ru}$ 配合 物作为催化剂实现对捕获的 $\mathrm{CO}_{2}$ 进行高选择性的氢化 还原为甲酸(表 5 , Entry 6). 反应条件相对温和, $P_{\mathrm{H}_{2}}=11$ $\mathrm{MPa}, T=130{ }^{\circ} \mathrm{C}$, TOF 可以达到 $990 \mathrm{~h}^{-1}$.

\section{2 有机胺捕集 $\mathrm{CO}_{2}$ 氢化还原为甲醇}

\subsection{1噁唑啉酮/环状碳酸酯的制备}

2015 年, Milstein 课题组 ${ }^{[82]}$ 报道了使用氨基醇作为 $\mathrm{CO}_{2}$ 捕获剂, 以 $\mathrm{Cs}_{2} \mathrm{CO}_{3}$ 作为催化剂, 可以在低压条件下 吸收 $\mathrm{CO}_{2}\left(P_{\mathrm{CO}_{2}}=0.1 \sim 0.3 \mathrm{MPa}\right)$, 生成相应的噁唑啉酮 化合物(Scheme 28). 随后, 在 Ru/PNN 三齿配合物催化 剂的作用下，可以将噁唑啉酮氢化为甲醇，收率为 $53 \%$, 氨基醇回收率为 $74 \%$.
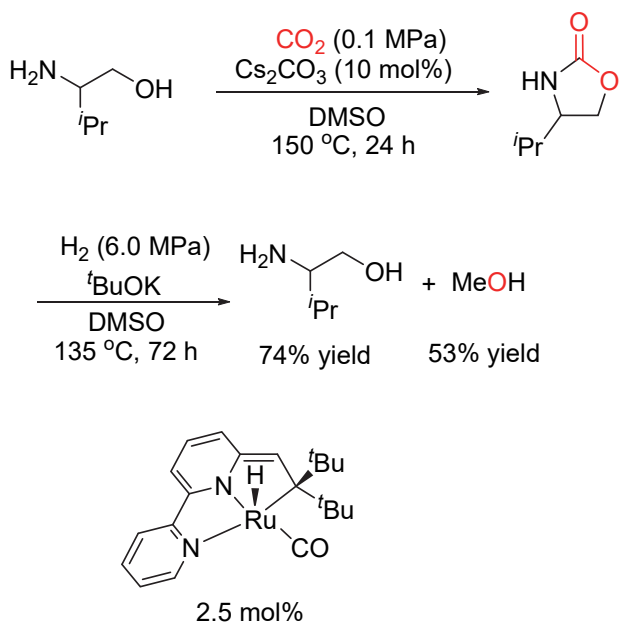

图式 28 啞唑啉酮氢化合成甲醇

Scheme 28 Hydrogenation of oxazolinone for the synthesis of methanol

\subsection{2 氨基甲酸盐/碳酸盐的制备}

上文中提到 Sanford 课题组 ${ }^{[80]}$ 发展的有机胺协助的 $\mathrm{CO}_{2}$ 氢化还原为甲醇的过程, 随后 Parakash 课题组 ${ }^{[100]}$ 采用 $\mathrm{CCU}$ 策略，使用有机胺作为 $\mathrm{CO}_{2}$ 捕获试剂，在室温 下向有机胺溶液中鼓入含有 $\mathrm{CO}_{2}$ 的混合气体生成氨基 甲酸盐和碳酸盐，随后使用过渡金属催化剂氢化捕集 $\mathrm{CO}_{2}$ 生成的中间体，从而实现了甲醇的合成(图 12). 对 于氨基甲酸盐的氢化本质上很可能是气体 $\mathrm{CO}_{2}$ 而不是 氨基甲酸盐的氢化，原因在于氨基甲酸盐具有富电子特 性，直接氢化较为困难. 使用聚多胺的水溶液具有四大 优点: (1)有利于放大反应, (2)低挥发度, (3)低成本, (3)方 便易得。使用五乙烯六胺(PEHA)作为 $\mathrm{CO}_{2}$ 捕获剂, Ru-Macho-BH (C-1)作为氢化的催化剂, 体系的收率可 以达到 79\%. 此外，该催化体系可以在保持较高活性的 前提下循环使用五次以上, 这是首例吸附空气中的 $\mathrm{CO}_{2}$ 将其氢化还原为甲醇的报道.

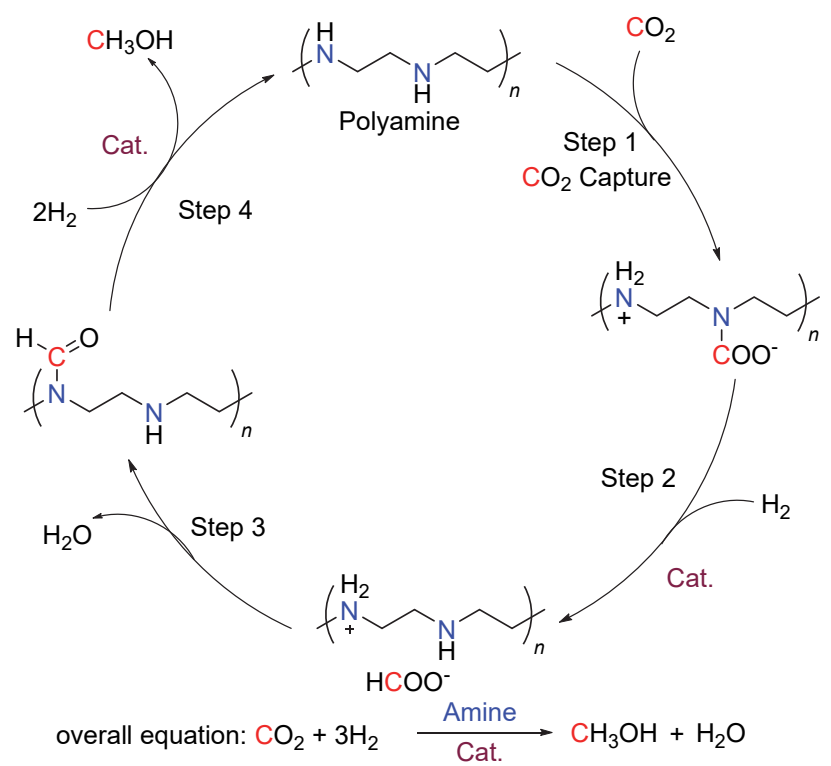

图 12 聚多胺捕集 $\mathrm{CO}_{2}$ 并原位氢化为甲醇

Figure $12 \mathrm{CO}_{2}$ capture and in situ hydrogenation to $\mathrm{CH}_{3} \mathrm{OH}$ using a polyamine

\section{3 氢氧化物作为 $\mathrm{CO}_{2}$ 捕获剂}

虽然有机胺和氨基醇能够有效地捕获 $\mathrm{CO}_{2}$, 但是这 两类捕获剂往往易挥发，因而造成环境污染. 相对而言, 氢氧化钠、氢氧化钾的水溶液具有低的饱和蒸气压，价 格便宜, 甚至能够与较低浓度的 $\mathrm{CO}_{2}$ 反应生成碳酸氢 盐. 因此氢氧化物是一类很理想的 $\mathrm{CO}_{2}$ 吸附材料. 虽然, 碳酸氢盐的氢化生成甲酸盐的报道较多 ${ }^{[47,101]}$, 但是直 到 2018 年, Parakash 课题组 ${ }^{[102]}$ 才报道了使用氢氧化钾 捕集 $\mathrm{CO}_{2}$ 并将其原位氢化生成甲酸盐(Scheme 29). 在氢 氧化物中, $\mathrm{NaOH} 、 \mathrm{KOH}$ 和 $\mathrm{CsOH}$ 在整个串联反应中展 
现出了很好的效果. 反应的第一步是氢氧化物与 $\mathrm{CO}_{2}$ 生 成碳酸氢盐, 随后在 $\mathrm{Ru}$ 和 $\mathrm{Fe}$ 配合物的存在下被还原为 甲酸盐. 在该体系中, 甲基四氢呋喃 $/ \mathrm{H}_{2} \mathrm{O}$ 两相体系对于 反应结束以后催化剂和产物的分离起到了决定性作用, 分离的催化剂可以重复使用多次, 而且活性得以保持. 使用氢氧化物捕获空气中的 $\mathrm{CO}_{2}$ 生成碳酸氢盐, 再进一 步还原为甲醇的过程还未能实现, 原因在于甲酸盐的不 可还原性，因为甲酸负离子会和金属中心发生强的配位 从而限制了其进一步还原为甲醇.

$$
\begin{aligned}
& \mathrm{CO}_{2} \text { capture by hydroxide and conversion to formate } \\
& \mathrm{CO}_{2} \text { captured as bicarbonate salts }
\end{aligned}
$$

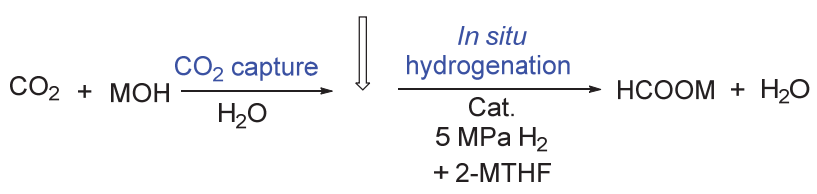

图式 29 聚多胺捕集 $\mathrm{CO}_{2}$ 并原位氢化为甲醇

Scheme $29 \mathrm{CO}_{2}$ capture and in situ hydrogenation to $\mathrm{CH}_{3} \mathrm{OH}$ using a polyamine

\section{$5 \mathrm{CO}_{2}$ 的间接催化氢化}

与 $\mathrm{CCU}$ 策略的相关报道非常类似的概念是 $\mathrm{CO}_{2}$ 的 间接氢化, 使用的是固定/捕集的 $\mathrm{CO}_{2}$, 或者是 $\mathrm{CO}_{2}$ 的衍 生物, 例如碳酸酯、噁唑啉酮、脲等, 经过还原反应生 成甲醇、甲酸或者甲酸盐. 整个过程被视为是 $\mathrm{CO}_{2}$ 的间 接氢化还原. 反应使用 $\mathrm{CO}_{2}$ 衍生物可以视为其中的 $\mathrm{C}$ $=\mathrm{O}$ 被预活化, 因此与气态 $\mathrm{CO}_{2}$ 氢化相比, 这种间接氢 化过程的反应条件往往更为温和 ${ }^{[103]}$.

近年来, $\mathrm{CO}_{2}$ 衍生物的氢化相关体系报道较多. Milstein 课题组 ${ }^{[78]}$ 报道了去芳香化的吡啶或者联吡啶骨架 的 Ru/PNN 配合物用于碳酸酯和氨基甲酸酯的氢化生成 甲醇(Scheme 30). 此外, 使用这种 $\mathrm{Ru}$ 催化剂还可以将 甲酸酯氢化为甲醇. 这些反应具有原子经济性高, 反应 条件温和, 中性条件下即可高效进行; 而且可以在无溶 剂条件下进行. 整个过程没有废弃物生成, 绿色环境友 好.

$[(\mathrm{PNN}) \mathrm{Ru}-(\mathrm{CO})(\mathrm{H})]$ 催化剂也可用于腿合成甲醇的 氢化 ${ }^{[78 b]}$ (Scheme 31). 氢化体系只需要 $2 \mathrm{~mol} \%$ 的 $\mathrm{Ru}$ 催 化剂, 在相对温和的条件下 $\left(P_{\mathrm{H}_{2}}=1.36 \mathrm{MPa}, T=\right.$ $\left.110{ }^{\circ} \mathrm{C}\right)$, 一系列腿衍生物被高效地还原为甲醇和胺. 机 理研究表明该反应涉及到甲酰胺中间体.

2012 年, 丁奎岭课题组 ${ }^{[104]}$ 报道了 $\mathrm{Ru} / \mathrm{PNP}$ 促进环 状碳酸酯的氢化合成甲醇以及二醇类化合物(Scheme 32), 这是一种经由碳酸乙烯酯氢化间接合成甲醇的策 略. 不同于传统的 Omega Shell 过程 ${ }^{[105]}$, 本方法采取的

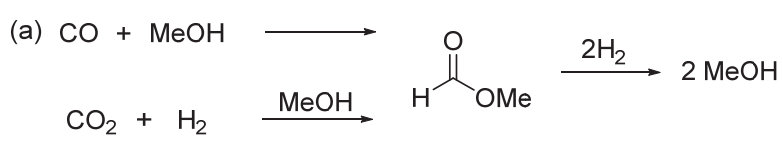

(b) $\mathrm{CO}+2 \mathrm{MeOH} \stackrel{1 / 2 \mathrm{O}_{2}}{-\mathrm{H}_{2} \mathrm{O}} \underset{\mathrm{MeO}}{\longrightarrow} \mathrm{CO}_{2}+2 \mathrm{MeOH} \stackrel{3}{\longrightarrow} 3 \mathrm{MeOH}$

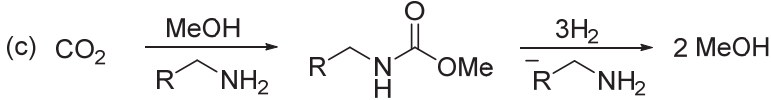

图式 30 催化甲酸酯、碳酸二甲酯和氨基甲酸酯的氢化合成 甲醇

Scheme 30 Alternative routes to methanol based on methyl formate, dimethyl carbonate and organo-carbamates.

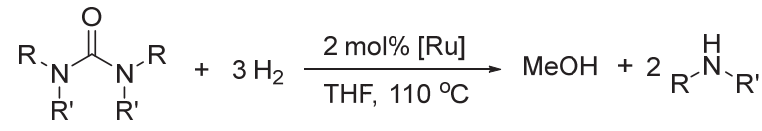

$$
\begin{aligned}
& \text { cat. }
\end{aligned}
$$

图式 $31 \mathrm{PNN} / \mathrm{Ru}$ 催化剂用于嫝衍生物的氢化反应 Scheme 31 Hydrogenation of urea derivatives using PNN pincer catalyst

是碳酸乙烯酯氢化的方式合成邻二醇和甲醇. 在相对温 和的反应条件下 $\left(P_{\mathrm{H}_{2}}=6 \mathrm{MPa} 135{ }^{\circ} \mathrm{C}, 72 \mathrm{~h}\right)$, 反应效率 非常高, 最高 TON 可达 $87000, \mathrm{TOF}=1200 \mathrm{~h}^{-1}$. 此外, 该催化体系还可以 $99 \%$ 的收率经由聚碳酸丙烯酯的氢 化降解制备甲醇和丙二醇.

通常来说, 用于 $\mathrm{CO}_{2}$ 间接氢化的催化剂主要是 Pincer 配合物，例如吡啶或联吡啶骨架的 PNN-Ru(II), CNN-Ru(II), Ru-Macho-BH 和有机胺骨架的 PNP-Ru(II) 配合物. 2019 年, 我们课题组 ${ }^{[103]}$ 报道了使用氮杂环丙烷 与 $\mathrm{CO}_{2}$ 反应生成的噁唑啉酮作为氢化反应的前驱体，在 $\mathrm{Pd} / \mathrm{C}$ 催化剂的存在下, 以 $\mathrm{H}_{2}$ 作为氢源实现了噁唑啉酮 的氢化反应生成甲酸, 同时生成直链的有机胺(Scheme 33). 该过程也可以理解为是对 $\mathrm{CO}_{2}$ 捕集后的原位氢化 反应，通过一系列条件篎选，反应可以获得很好的甲酸 收率(42\% 92\%)以及 2-芳基胺收率(63\%～98\%).

\section{6 总结与展望}

$\mathrm{CO}_{2}$ 是一种非常有用的 $\mathrm{C}_{1}$ 资源, 使用均相催化氢化 的策略对其进行合理利用，可以减少对化石原料的依 赖、缓解全球的能源危机以及温室效应等环境问题. 通 过使用不同的催化体系，主要为贵金属催化剂以及廉价 金属催化剂两大类，可以将 $\mathrm{CO}_{2}$ 分别还原为甲酸、甲酰 


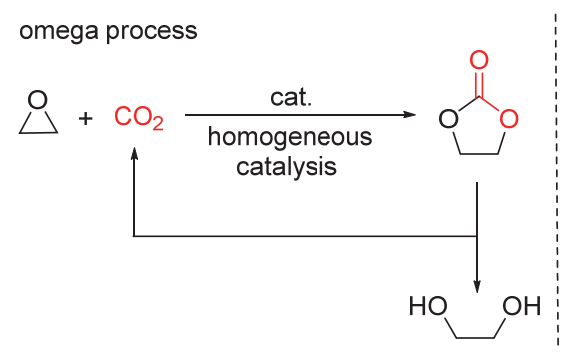

hydrogenation of carbonates

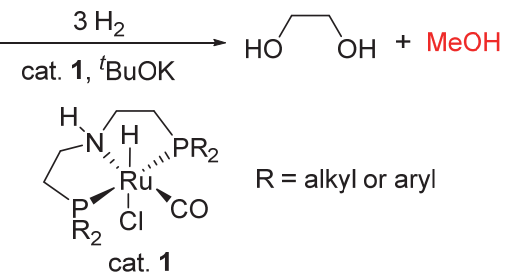

图式 32 碳酸酯催化氢化为甲醇

Scheme 32 Hydrogenation of carbonates to produce methanol

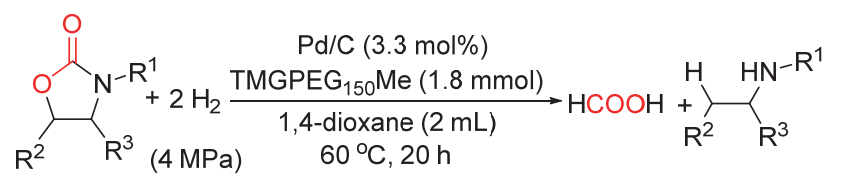

图式 33 啞唑啉酮的氢化合成甲酸

Scheme 33 Hydrogenation of 5-aryl-2-oxazolidinones to produce formic acid

胺、甲酸酯、甲醛、甲醇和 $\mathrm{C}_{2}$ +醇等产物. 从目前相关 的报道来看，贵金属催化剂，例如 $\mathrm{Ru} 、 \mathrm{Rh} 、 \mathrm{Ir}$ 等配合物 对于 $\mathrm{CO}_{2}$ 的两电子氢化还原至甲酸、甲酰胺和甲酸酯等 产物具有很好的催化活性; 而廉价金属催化效率相对较 低，例如 $\mathrm{Fe} 、 \mathrm{Co} 、 \mathrm{Ni}$ 和 $\mathrm{Cu}$ 等. 在氢化反应中，对于 $\mathrm{CO}_{2}$ 的四电子还原至甲醛以及六电子还原至甲醇的诸多报 道中, 同样是贵金属催化剂展现出了很好的催化活性, 而廉价金属对于相关转化的报道则较少. 催化剂使用的 配体主要是膦配体(单膦配体、双齿膦配体、多齿膦配 体等)、氮膦配体、氮氧配体等，相对而言氮膦配体活性 最高, 应用最为广泛.

对于 $\mathrm{CO}_{2}$ 的催化氢化研究领域, 目前主要存在的研 究挑战在于: (1)目前报道的催化体系往往是贵金属, 经 济成本较高, 因此如何提升廉价金属的催化活性成为了 关键问题; (2)对于氢气作为氢源的 $\mathrm{CO}_{2}$ 氢化反应, 氢气 的清洁制备也有较大的挑战, 因此工业上开发高效的产 氢利用可再生电能或太阳能等尤为重要; (3)对于 $\mathrm{CCU}$ 策略在 $\mathrm{CO}_{2}$ 氢化反应中的应用, 还有很多的科学问题亟 待解决，例如开发更为新颖廉价的 $\mathrm{CO}_{2}$ 捕集方式等; (4) 目前的氢化反应研究, 基础研究向工业生产转化成功的 例子较少, 因此开发能够实现工业化生产的催化氢化体 系是亟待解决的重大课题之一. $\mathrm{CO}_{2}$ 催化氢化的大规模 工业化应用势必会促进碳中和进程, 实现人类社会的可 持续发展.

\section{References and note}

[1] https://www.iea.org/reports/global-energy-co2-statusreport-2019.

[2] Wuebbles, D. J.; Easterling, D. R.; Hayhoe, K.; Knutson, T.; Kopp, R. E.; Kossin, J. P.; Kunkel, K. E.; LeGrande, A. N.; Mears, C.; Sweet, W. V.; Taylor, P. C.; Vose, R. S.; Wehner, M. F. In Climate Science
Special Report: Fourth National Climate Assessment, Vol. I, U.S. Global Change Research Program, Washington, DC, 2017, pp. 35 72.

[3] (a) Zhang, L. L.; Han, Z. B.; Zhang, L.; Li, M. X.; Ding, K. L. Chin J. Org. Chem. 2016, 36, 1824 (in Chinese).

(张琳莉, 韩召斌, 张否, 李明星, 丁奎岭, 有机化学, 2016, 36, 1824.)

(b) Dong, K. W.; Razzaq, R.; Hu, Y. Y.; Ding, K. L. Top. Curr. Chem. 2017, 375, 23 .

(c) Li, Y.; Wang, Z.; Liu, Q. Chin. J. Org. Chem. 2017, 37, 1978 (in Chinese).

(李勇, 王征, 刘庆彬, 有机化学, 2017, 37, 1978.)

(d) Zhang, W. Z.; Zhang, N.; Guo, C. X.; Lu, X. B. Chin. J. Org. Chem. 2017, 37, 1309 (in Chinese)

(张文珍，张宁，郭春晓，吕小兵，有机化学, 2017, 37, 1309.)

(e) Tortajada, A.; Juliá-Hernández, F.; Börjesson, M.; Moragas, T.; Martin, R. Angew. Chem., Int. Ed. 2018, 57, 15948.

(f) Wang, Q.; Sun, J. Chem. Bull. 2018, 81, 312 (in Chinese).

(王强，孙京，化学通报, 2018, 81, 312.)

(g) Zhang, Y.; Cen, J.; Xiong, W.; Qi, Z.; Jiang, H. Prog. Chem. 2018, 30, 547 (in Chinese)

(张宇，岑竞鹤，熊文芳，戚朝荣，江焕峰，化学进展，2018，30, 547.)

(h) Wang, S.; Xi, C. Chem. Soc. Rev. 2019, 48, 382

(i) Chen, L.; Xie, J. H. Chin. J. Org. Chem. 2020, 40, 247 (in Chinese).

(程否, 谢建华, 有机化学, 2020, 40, 247.)

(j) Ye, J. H.; Ju, T.; Huang, H.; Liao, L. L.; Yu, D. G. Acc. Chem. Res 2021, 54, 2518.

(k) Yi, Y. P.; Hang, W.; Xi, C. J. Chin. J. Org. Chem. 2021, 41, 80 (in Chinese).

(易雅平，杭炜，席婵娟，有机化学, 2021, 41, 80.)

(o) Zhang, Z.; Gong, L.; Zhou, X. Y.; Yan, S. S.; Li J.; Yu, D. G. Acta Chim. Sinica 2019, 77, 783 (in Chinese)

(张振, 龚莉, 周晓渝, 颜思顺, 李静, 余达刚, 化学学报, 2019, 77, 783.)

(p) Zhou, C.; Li, M.; Yu, J. T.; Sun, S.; Cheng, J. Chin. J. Org. Chem. 2020, 40, 2221 (in Chinese).

(周聪, 李渺，于金涛，孙松，成江，有机化学, 2020, 40, 2221.)

(q) Chen, K. H.; Li, H. R.; He, L. N. Chin. J. Org. Chem. 2020, 40 2195.

(陈凯宏，李红茹，何良年，有机化学, 2020, 40, 2195.)

(r) Guo, X.; Wang, Y. Z.; Chen, J.; Li, G. Q.; Xia, J. B. Chin. J. Org. Chem. 2020, 40, 2208 (in Chinese).

(郭霄，王亚洲，陈洁，李公强，夏纪宝，有机化学，2020，40, 2208.)

[4] Leitner W. Angew. Chem., Int. Ed. 1995, 34, 2207.

[5] (a) Boddien, A.; Mellmann, D.; Gärtner, F.; Jackstell, R.; Junge, H.; Dyson, P. J.; Laurenczy, G.; Ludwig, R.; Beller, M. Science 2011 $333,1733$.

(b) Sordakis, K.; Tang, C. H.; Vogt, L. K.; Junge, H.; Dyson, P. J.; Beller, M.; Laurenczy, G. Chem. Rev. 2018, 118, 372.

[6] Ding, S. T.; Jiao, N. Angew. Chem., Int. Ed. 2012, 51, 9226.

[7] Álvarez, A.; Bansode, A.; Urakawa, A.; Bavykina, A. V.; Wezendonk, 
T. A.; Makkee, M.; Gascon, J.; Kapteijn, F. Chem. Rev. 2017, 117, 9804.

[8] Sordakis, K, Tang, C. H.; Vogt, L. K.; Junge, H.; Dyson, P. J.; Beller, M.; Laurenczy, G. Chem. Rev. 2018, 118, 372.

[9] Farlow, M. W.; Adkins, H. J. Am. Chem. Soc. 1935, 57, 2222.

[10] Inoue, Y.; Izumida, H.; Sasaki, Y.; Hashimoto, H. Chem. Lett. 1976, 863.

[11] Jessop, P. G.; Ikariya, T.; Noyori, R. Nature 1994, 368, 231.

[12] Jessop, P. G.; Hsiao, Y.; Ikariya, T.; Noyori, R. J. Am. Chem. Soc. 1994, 116, 8851.

[13] Kröcher, O.; Köppel, R. A.; Baiker, A. Chem. Commun. 1997, 453.

[14] Munshi, P.; Main, A. D.; Linehan, J. C.; Tai, C. C.; Jessop, P. G. J. Am. Chem. Soc. 2002, 124, 7963.

[15] Himeda, Y.; Onozawa-Komatsuzaki, N.; Sugihara, H.; Arakawa, H.; Kasuga, K. Organometallics 2004, 23, 1480.

[16] Federsel, C.; Jackstell, R.; Boddien, A.; Laurenczy, G.; Beller, M. ChemSusChem 2010, 3, 1048.

[17] Sanz, S.; Azua, A.; Peris, E. Dalton Trans. 2010, 39, 6339.

[18] Liu, Q.; Wu, L.; Gulak, S.; Rockstroh, N.; Jackstell, R.; Beller, M. Angew. Chem., Int. Ed. 2014, 53, 7085.

[19] Kothandaraman, J.; Czaun, M.; Goeppert, A.; Haiges, R.; Jones, J. P.; May, R. B.; Prakash, G. K. S.; Olah, G. A. ChemSusChem 2015, 8, 1442 .

[20] Huff, C. A.; Sanford, M. S. ACS Catal. 2013, 3, 2412.

[21] Zhang, L.; Han, Z.; Zhao, X.; Wang, Z.; Ding, K. Angew. Chem., Int. Ed. 2015, 54, 6186.

[22] Rohmann, K.; Kothe, J.; Haenel, M. W.; Englert, U.; Hölscher, M.; Leitner, W. Angew. Chem., Int. Ed. 2016, 55, 8966.

[23] Weilhard, A.; Qadir, M. I. Sans, V. Dupont, J. ACS Catal. 2018, 8, 1628 .

[24] Zhang, F. H.; Liu, C.; Li, W.; Tian, G. L.; Xie, J. H.; Zhou, Q. L. Chin. J. Chem. 2018, 36, 1000.

[25] Westhues, N.; Belleflamme, M.; Klankermayer, J. ChemCatChem 2019, 11, 5269 .

[26] Malaza, S. S. P.; Makhubela, B. C. E. Journal of $\mathrm{CO}_{2}$ Utilization 2020, 39, 101149 .

[27] Tsai, J. C.; Nicholas, K.M. J. Am. Chem. Soc. 1992, 114, 5117.

[28] Hutschka, F.; Dedieu, A.; Eichberger, M.; Fornika, R.; Leitner, W. J. Am. Chem. Soc. 1997, 119, 4432.

[29] Zhang, J. J.; Qian, Q. L.; Wang, Y.; Bediako, B. B.; Cui, M.; Yang, G. Y.; Han, B. X. Green Chem. 2019, 21, 233.

[30] Laureanti, J. A.; Buchko, G. W.; Katipamula, S.; Su, Q.; Linehan, J. C.; Zadvornyy, O. A.; Peters, J. W.; O’Hagan, M. ACS Catal. 2019, 9, 620 .

[31] Gassner, F.; Leitner, W. J. Chem. Soc., Chem. Commun. 1993, 1465.

[32] Ezhova, N. N.; Kolesnichenko, N. V.; Bulygin, A. V.; Slivinskii, E. V.; Han, S. Russ. Chem. Bull. 2002, 51, 2165.

[33] Li, Y. N.; He, L. N.; Liu, A. H.; Lang, X. D.; Yang, Z. Z.; Yu, B.; Luan, C. R. Green Chem. 2013, 15, 2825

[34] Himeda, Y.; Onozawa-Komatsuzaki, N.; Sugihara, H.; Arakawa, H.; Kasuga, K. Organometallics 2004, 23, 1480.

[35] Himeda, Y.; Onozawa-Komatsuzaki, N.; Sugihara, H.; Kasuga, K. Organometallics 2007, 26, 702.

[36] Ogo, S.; Kabe, R; Hayashi, H.; Harada, R.; Fukuzumi, S. Dalton Trans. 2006, 4657.

[37] Tanaka, R.; Yamashita, M.; Nozaki, K. J. Am. Chem. Soc. 2009, 131, 14168.

[38] Schmeier, T. J.; Dobereiner, G. E.; Crabtree, R. H.; Hazari, N. J. Am. Chem. Soc. 2011, 133, 9274.

[39] Azua, A.; Sanz, S.; Peris, E. Chem.-Eur. J. 2011, 17, 3963.

[40] Liu, C.; Xie, J. H.; Tian, G. L.; Li, W.; Zhou, Q. L. Chem. Sci. 2015, $6,2928$.

[41] Fidalgo, J.; Ruiz-Castañeda, M.; García-Herbosa, G.; Carbayo, A.; Jalón, F. A.; Rodríguez, A. M.; Manzano, B. R.; Espino, G. Inorg. Chem. 2018, 57, 14186.

[42] Kanega, R.; Ertem, M. Z.; Onishi, N.; Szalda, D. J.; Fujita, E. Organometallics 2020, 39, 1519.

[43] Hull, J. F.; Himeda, Y.; Wang, W. H.; Hashiguchi, B.; Periana, R.;
Szalda, D. J.; Muckerman, J. T.; Fujita, E. Nat. Chem. 2012, 4, 383.

[44] Lu, S. M.; Wang, Z.; Li, J.; Xiao, J.; Li, C. Green Chem. 2016, 18, 4553.

[45] Evans, G. O.; Newell, C. J. Inorg. Chim. Acta 1978, 31, L387.

[46] Tai, C. C.; Chang, T.; Roller, B.; Jessop, P. G. Inorg. Chem. 2003, 42, 7340 .

[47] Federsel, C.; Boddien, A.; Jackstell, R.; Jennerjahn, R.; Dyson, P. J.; Scopelliti, R.; Laurenczy, G.; Beller, M. Angew. Chem., Int. Ed. 2010, 49, 9777.

[48] Ziebart, C.; Federsel, C.; Anbarasan, P.; Jackstell, R.; Baumann, W.; Spannenberg, A.; Beller, M. J. Am. Chem. Soc. 2012, 134, 20701

[49] Montandon-Clerc, M.; Laurenczy, G. J. Catal. 2018, 362, 78.

[50] Bertini, F.; Gorgas, N.; Stöger, B.; Peruzzini, M.; Veiros, L. F.; Kirchner, K.; Gonsalvi, L. ACS Catal. 2016, 6, 2889.

[51] Jayarathne, U.; Hazari, N.; Bernskoetter, W. H. ACS Catal. 2018, 8, 1338.

[52] (a) Liu, W. P.; Sahoo, B.; Junge, K.; Beller, M. Acc. Chem. Res. 2018, 51,1858 .

(b) Federsel, C.; Ziebart, C.; Jackstell, R.; Baumann, W.; Beller, M. Chem.-Eur. J. 2012, 18, 72 .

[53] Tai, C. C.; Chang, T.; Roller, B.; Jessop, P. G. Inorg. Chem. 2003, 42, 7340.

[54] Affan, M. A.; Jessop, P. G. Inorg. Chem. 2017, 56, 7301.

[55] Affan, M. A.; Schatte, G.; Jessop, P. G. Inorg. Chem. 2020, 59, 14275.

[56] Watari, R.; Kayaki, Y.; Hirano, S.; Matsumoto, N.; Ikariya, T. $A d v$. Synth. Catal. 2015, 357, 1369.

[57] Zall, C. M.; Linehan, J. C.; Appel, A. M. ACS Catal. 2015, 5, 5301.

[58] Li, R. P.; Zhao, Y. F.; Li, Z. Y.; Wu, Y. Y.; Wang, J. J.; Liu, Z. M. Sci. China Chem. 2019, 62, 256.

[59] (a) Du, C. Y.; Chen, Y. F. Acta Chim. Sinica 2020, 78, 938 (in Chinese).

(杜重阳，陈耀峰，化学学报, 2020, 78, 938.)

(b) Du, C. Y.; Chen, Y. F. Chin. J. Chem. 2020, 38, 1057.

[60] Langer, R.; Diskin-Posner, Y.; Leitus, G.; Shimon, L. J. W.; Ben-David, Y.; Milstein, D. Angew. Chem., Int. Ed. 2011, 50, 9948.

[61] Zhang, Y.; MacIntosh, A. D.; Wong, J. L.; Bielinski, E. A.; Williard, P. G.; Mercado, B. Q.; Hazari, N.; Bernskoetter, W. H. Chem. Sci. 2015, 6, 4291 .

[62] Bertini, F.; Mellone, I.; Ienco, A.; Peruzzini, M.; Gonsalvi, L. ACS Catal. 2015, 5, 1254

[63] Zhu, F.; Zhu-Ge, L.; Yang, G.; Zhou, S. ChemSusChem 2015, 8, 609.

[64] Federsel, C.; Ziebart, C.; Jackstell, R.; Baumann, W.; Beller, M. Chem.-Eur. J. 2012, 18, 72 .

[65] Jeletic, M. S.; Mock, M. T.; Appel, A. M.; Linehan, J. C. J. Am. Chem. Soc. 2013, 135, 11533.

[66] Badiei, Y. M.; Wang, W.-H.; Hull, J. F.; Szalda, D. J.; Muckerman, J. T.; Himeda, Y.; Fujita, E. Inorg. Chem. 2013, 52, 12576.

[67] Spentzos, A. Z.; Barnes, C. L.; Bernskoetter, W. H. Inorg. Chem. 2016, 55, 8225 .

[68] Enthaler, S.; Bruck, A.; Kammer, A.; Junge, H.; Irran, E.; Gulak, S. ChemCatChem 2015, 7, 65.

[69] Zhang, Y. Y.; Williard, P. G.; Bernskoetter, W. H. Organometallics 2016, 35, 860 .

[70] Reuss, G.; Disteldorf, W.; Gamer, A. O.; Hilt, A. In UllmannÏs Encyclopedia of Industrial Chemistry, Wiley-VCH, Weinheim, 2000.

[71] Bontemps, S.; Vendier, L.; Sabo-Etienne, S. J. Am. Chem. Soc. 2014, 136, 4419.

[72] Ren, X. Y.; Zheng, Z. Y.; Zhang, L.; Wang, Z.; Xia, C. G.; Ding, K. L. Angew. Chem. 2017, 129, 316.

[73] Hua, K. M.; Liu, X. F.; Wei, B. Y.; Shao, Z. L.; Deng, Y. C.; Zhong, L. S.; Wang, H.; Sun, Y. H. Green Chem. 2021, DOI: 10.1039/d0gc03913f.

[74] (a) Arpe, H. J. Industrial Organic Chemistry, Vol. 5, Wiley-VCH, Weinheim, 2010.

(b) Bertau, M.; Offermanns, H.; Plass, L.; Schmidt, F.; Wernicke, H. J. Methanol: The Basic Chemical and Energy Feedstock of the Future, Springer, Amsterdam, 2013.

(c) Baerns, M.; Behr, A.; Brehm, A.; Gmehling, J.; Hofmann, H.; 
Onken, U.; Renken, A. Technische Chemie, Wiley-VCH, Weinheim, 2006.

[75] (a) Gaikwad, R.; Bansode, A.; Urakawa, A. J. Catal. 2016, 343, 127. (b) Xie, S.; Zhang, W.; Lan, X.; Lin, H. ChemSusChem 2020, 13, 6141 .

[76] Jessop, P. G. In The Handbook of Homogeneous Hydrogenation, Eds.: de Vries, J. G.; Elsevier, C. J., Wiley-VCH, Weinheim, 2007, p. 489.

[77] (a) Tominaga, K. I.; Sasaki, Y.; Kawai, M.; Watanabe, T.; Saito, M. J. Chem. Soc. Chem. Commun. 1993, 629.

(b) Tominaga, K. i.; Sasaki, Y.; Watanabe, T.; Saito, M. Bull. Chem. Soc. Jpn. 1995, 68, 2837.

[78] (a) Balaraman, E.; Gunanathan, C.; Zhang, J.; Shimon, L. J. W.; Milstein, D. Nat. Chem. 2011, 3, 609.

(b) Balaraman, E.; Ben-David, Y.; Milstein, D. Angew. Chem., Int. Ed. 2011, 50, 11702 .

(c) Balaraman, E.; Gnanaprakasam, B.; Shimon, L. J. W.; Milstein, D. J. Am. Chem. Soc. 2010, 132, 16756.

[79] Huff, C. A.; Sanford, M. S. J. Am. Chem. Soc. 2011, 133, 18122.

[80] Rezayee, N. M.; Huff, C. A.; Sanford, M. S. J. Am. Chem. Soc. 2015, 137, 1028.

[81] Wesselbaum, S.; Stein, T. v.; Klankermayer, J.; Leitner, W. Angew. Chem., Int. Ed. 2012, 51, 7499.

[82] Khusnutdinova, J. R.; Garg, J. A.; Milstein, D. ACS Catal. 2015, 5, 2416.

[83] Qian, Q. L.; Cui, M.; He, Z. H.; Wu, C. Y.; Zhu, Q. G.; Zhang, Z. F.; Ma, J.; Yang, G. Y.; Zhang, J. J.; Han, B. X. Chem. Sci. 2015, 6, 5685.

[84] Thenert, K.; Beydoun, K.; Wiesenthal, J.; Leitner, W.; Klankermayer, J. Angew. Chem., Int. Ed. 2016, 55, 12266.

[85] Wang, Z.; Zhao, Z. W.; Li, Y.; Zhong, Y. X.; Zhang, Q. Y.; Liu, Q. B.; Solan, G. A.; Ma, Y. P.; Sun, W. H. Chem. Sci. 2020, 11, 6766.

[86] Schieweck, B. G.; Jurling-Will, P.; Klankermayer, J. ACS Catal. 2020, 10, 3890 .

[87] Ribeiro, A. P. C.; L. Martins, M. D. R. S.; Pombeiro, A. J. L. Green Chem. 2017, 19, 4811

[88] Lane, E. M.; Zhang, Y.; Hazari, N.; Bernskoetter, W. H. Organometallics 2019, 38, 3084 .

[89] (a) Gui, Y. Y.; Hu, N. F.; Chen, X. W.; Liao, L. L.; Ju, T.; Ye, J. H.; Zhang, Z.; Li, J.; Yu, D. G. J. Am. Chem. Soc. 2017, 139, 17011.

(b) Qiu, J.; Gao, S.; Li, C. P.; Zhang, L.; Wang, Z.; Wang, X. M.; Ding, K. L. Chem.-Eur. J. 2019, 25, 13874.

(c) Chen, X. W.; Zhu, L.; Gui, Y. Y.; Jing, K.; Jiang, Y. X.; Bo, Z. Y.; Lan, Y.; Li, J.; Yu, D. G. J. Am. Chem. Soc. 2019, 141, 18825.

(d) Wang, M. Y.; Jin, X.; Wang, X. F.; Xia, S. M.; Wang, Y.; Huang, S. Y.; Li, Y.; He, L. N.; Ma, X. B. Angew. Chem., Int. Ed. 2021, 60, 3984.

[90] (a) Bara, J. E.; Carlisle, T. K.; Gabriel, C. J.; Camper, D.; Finotello, A.; Gin, D. L.; Noble, R. D. Ind. Eng. Chem. Res. 2009, 48, 2739. (b) Wang, C. M.; Luo, H. M.; Jiang, D. E.; Li, H. R.; Dai, S. Angew. Chem., Int. Ed. 2010, 49, 5978.

[91] (a) Li, Y. N.; He, L. N.; Liu, A. H.; Lang, X. D.; Yang, Z. Z.; Yu, B.; Luan, C. R. Green Chem. 2013, 15, 2825.

(b) Yang, Z. Z.; He, L. N.; Gao, J.; Liu, A. H.; Yu, B. Energy Environ. Sci. 2012, 5, 6602 .

(c) Kar, S.; Goeppert, A.; Surya Prakash, G. K. Acc. Chem. Res. 2019, $52,2892$.

[92] (a) Yang, Z. Z.; Zhao, Y. N.; He, L. N. RSC Adv. 2011, 1, 545.

(b) Yang, Z. Z.; He, L. N.; Zhao, Y. N.; Li, B.; Yu, B. Energy Environ. Sci. 2011, 4, 3971

(c) Liu, A. H.; Ma, R.; Song, C.; Yang, Z. Z.; Yu, A.; Cai, Y.; He, L. N.; Zhao, Y. N.; Yu, B.; Song, Q. W. Angew. Chem., Int. Ed. 2012, 51, 11306.

(d) Li, Y. N.; He, L. N.; Diao, Z. F.; Yang, Z. Z. Carbon Capture with Simultaneous Activation and Its Subsequent Transformation, Eds.: Eldik, van R.; Aresta, M., Vol. 66 (ISBN 978-0-12-420221-4), In Ad- vances in Inorganic Chemistry, Academic Press, Burlington, 2014, p. 289.

(e) Markewitz, P.; Kuckshinrichs, W.; Leitner, W.; Linssen, J.; Zapp, P.; Bongartz, R.; Schreiber, A.; MÜller, T. E. Energy Environ. Sci. 2012, 5, 7281.

(f) Li, Y. N.; He, L. N. Chin. Sci. Bull. 2015, 60, 1465 (in Chinese). (李雨浓，何良年，科学通报, 2015, 60, 1465.)

(g) Fu, H. C.; You, F.; Li, H. R.; He, L. N. Front. Chem. 2019, 7, 525

[93] (a) Su, J.; Lu, M.; Lin, H. Green Chem. 2015, 17, 2769.

(b) Moret, S.; Dyson, P. J.; Laurenczy, G. Nat. Commun. 2014, 5, 4017.

(c) Schuchmann, K.; Müller, V. Science 2013, 342, 1382.

(d) Wang, W. H.; Himeda, Y.; Muckerman, J. T.; Manbeck, G. F.; Fujita, E. Chem. Rev. 2015, 115, 12936.

(e) Zhao, T.; Hu, X.; Wu, Y.; Zhang, Z. Angew. Chem., Int. Ed. 2019 , 58,722 .

(f) Scott, M.; Blas Molinos, B.; Westhues, C.; Franciò, G.; Leitner, W. ChemSusChem 2017, 10, 1085.

[94] Li, Y. N.; He, L. N.; Liu, A. H.; Lang, X. D.; Yang, Z. Z.; Yu, B.; Luan, C. R. Green Chem. 2013, 15, 2825.

[95] Zhang, S.; Li, Y. N.; Zhang, Y. W.; He, L. N.; Yu, B.; Song, Q. W.; Lang, X. D. ChemSusChem 2014, 7, 1484.

[96] Li, Y.-N.; He, L.-N.; Lang, X.-D.; Liu, X.-F.; Zhang, S. RSC Adv. 2014, 4, 49995.

[97] McNamara, N. D.; Hicks, J. C. ChemSusChem 2014, 7, 1114.

[98] Kothandaraman, J.; Goeppert, A.; Czaun, M.; Olah, G. A.; Surya Prakash, G. K. Green Chem. 2016, 18, 5831.

[99] Guan, C.; Pan, Y.; Ang, E. P. L.; Hu, J.; Yao, C.; Huang, M. H.; Li, H.; Lai, Z.; Huang, K. W. Green Chem. 2018, 20, 4201.

[100] Kothandaraman, J.; Goeppert, A.; Czaun, M.; Olah, G. A.; Surya Prakash, G. K. J. Am. Chem. Soc. 2016, 138, 778.

[101] (a) Boddien, A.; Gärtner, F.; Federsel, C.; Sponholz, P.; Mellmann, D.; Jackstell, R.; Junge, H.; Beller, M. Angew. Chem., Int. Ed. 2011, 50,6411 .

(b) Langer, R.; Diskin-Posner, Y.; Leitus, G.; Shimon, L. J. W.; Ben-David, Y.; Milstein, D. Angew. Chem., Int. Ed. 2011, 50, 9948.

(c) Kothandaraman, J.; Czaun, M.; Goeppert, A.; Haiges, R.; Jones, J. P.; May, R. B.; Surya Prakash, G. K.; Olah, G. A. ChemSusChem 2015, $8,1442$.

(d) Dai, Z.; Luo, Q.; Cong, H.; Zhang, J.; Peng, T. New J. Chem. 2017, 41, 3055 .

(e) Bertini, F.; Mellone, I.; Ienco, A.; Peruzzini, M.; Gonsalvi, L. ACS Catal. 2015, 5, 1254

[102] Kar, S.; Goeppert, A.; Galvan, V.; Chowdhury, R.; Olah, J.; Surya Prakash, G. K. J. Am. Chem. Soc. 2018, 140, 16873.

[103] Li, Y. N.; Liu, X. F.; He, L. N. J. CO Util. 2019, 29, 74.

[104] Han, Z. B.; Rong, L.; Wu, J.; Zhang, L.; Wang, Z.; Ding, K. L. Angew. Chem., Int. Ed. 2012, 51, 13041.

[105] (a) The omega process (the only advanced mono EG process) is a process in which ethylene oxide is reacted with $\mathrm{CO}_{2}$ to first afford ethylene carbonate, followed by catalytic hydrolysis of the carbonate to selectively produce mono EG, which is an important component of automotive antifreeze and a key precursor to polyester, with global demands of over 25 million metric tons in 2010 . The prices of ethylene epoxide, $\mathrm{CO}_{2}$, and EG are 1600, 50, and $1300 \mathrm{US} \$$ /metric ton, respectively.

(b) Ma, J.; Sun, N.; Zhang, X.; Zhao, N.; Mao, F.; Wei, W.; Sun, Y. Catal. Today 2009, 148, 221.

[106] Balaraman, E.; Gunanathan, C.; Zhang, J.; Shimon, L. J. W.; Milstein, D. Nat. Chem. 2011, 3, 609 .

[107] Kar, S.; Goeppert, A.; Kothandaraman, J.; Prakash, G. K. S. ACS Catal. 2017, 7, 6347

[108] Schneidewind, J.; Adam, R.; Baumann, W.; Jackstell, R.; Beller, M. Angew. Chem., Int. Ed. 2017, 56, 1890.

(Lu, Y.) 